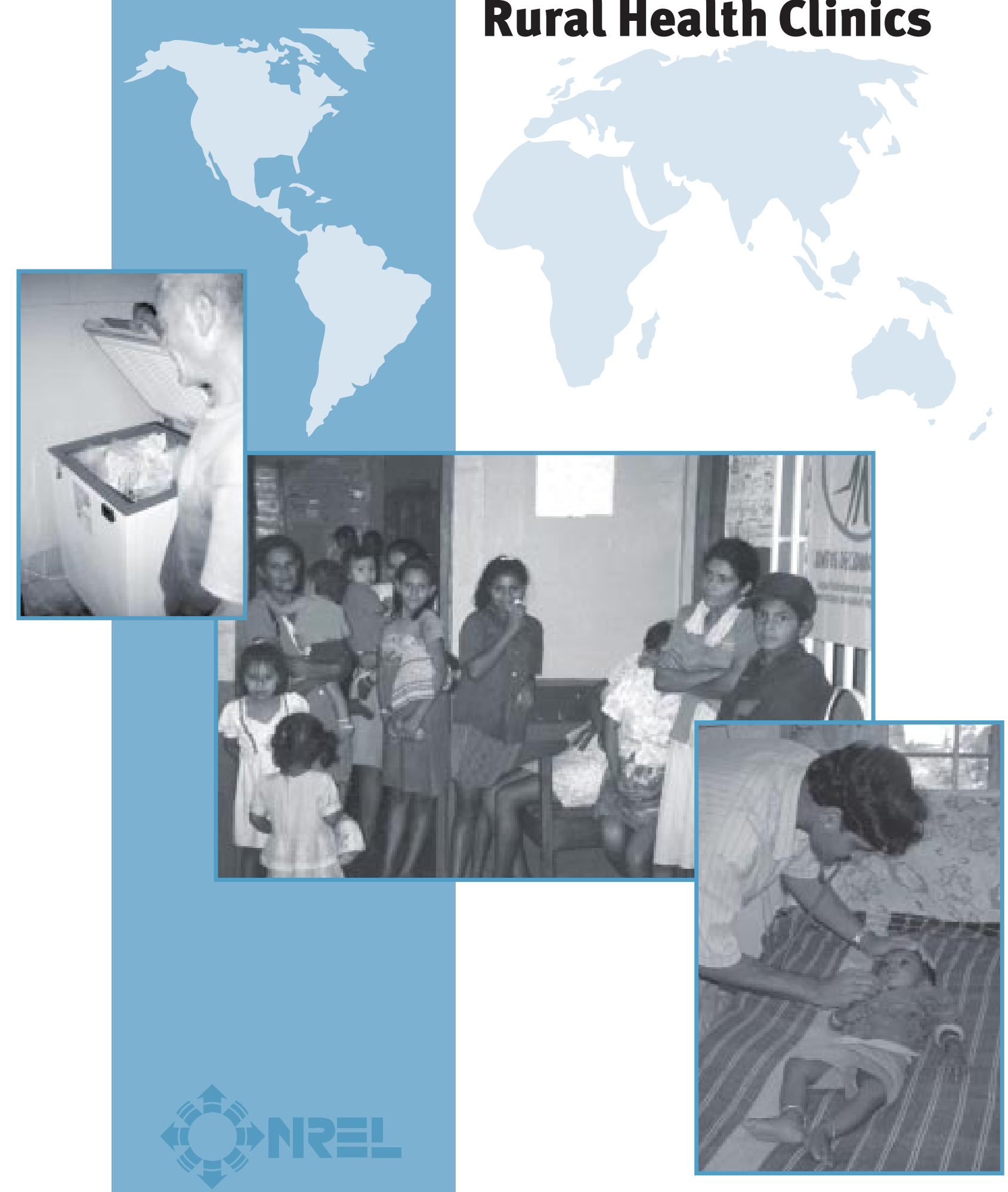

Renewable Energy for Rural Health Clinics 


\section{Cover Photos:}

Left: A photovoltaic powered vaccine refrigerator is used at a health clinic in Ghana.

Roger Taylor, NREL/PIX05504

Center: Patients seek the most basic of primary health care services at Clinica San Martin near Matagalpa, Nicaragua. Ken Olson, SEI/PIX06486

Right: A local village doctor treats a child at a clinic in India powered by photovoltaics. Jim Welch, Remote Power/PIX06006 


\section{Renewable Energy for Rural Health Clinics}

Antonio C. Jimenez

National Renewable Energy Laboratory

Ken Olson

Solar Energy International

September 1998

Published by the

National Renewable Energy Laboratory

1617 Cole Boulevard

Golden, Colorado 80401-3393

United States of America 


\section{FOREWORD}

Over the past 20 years the Expanded Programme on Immunization of the World Health Organization (WHO/EPI) has played a leading role in evaluating the possibility of using various types of energy sources for the vaccine Cold Chain. This was done in close collaboration with major partners such as NASA (National Aeronautics and Space Administration), UNICEF (United Nations Children's Fund), and USAID (United States Agency for International Development) and with the recipient countries, mostly in South America and Africa. Rapidly, it became obvious that solar energy was a technology that would play a critical role to ensure good-quality and safe vaccine refrigeration in remote health centers.

Gradually, as solar refrigeration technology was becoming standardized and therefore more reliable, large scale programmes were launched in Uganda, Zaire, Peru, Myanmar, and Indonesia, to name only a few.

Although use of solar refrigeration has enabled national immunization programmes to expand their outreach to remote populations and to ensure that good quality vaccines were delivered to the children and their mothers, evaluations of these programmes have highlighted several weaknesses, which remain to be addressed. One of the major problems facing the introduction of renewable energy technology remains its relatively high cost. Too often, "renewable energy advocates" minimize the high initial capital cost of the technology and argue that recurrent costs are negligible. Unfortunately, although recurrent costs are indeed low, they exist. Batteries must be replaced after a number of years (five years in the best cases and sometimes at a shorter interval, depending on their quality and their match with the whole system). If nothing is done at country level to plan and budget for the replacement of these batteries (equipment, manpower, and transport to the sites), then an excellent technology becomes useless and increases the number of "dead" systems laying around in remote areas discrediting the image of renewable energy.

This is why, over the past few years, WHO/EPI has been looking at ways to use renewable energy technology for a broader range of applications that could serve the needs of the rural health center and the community at large. The underlying motivation of this approach was that, by providing a number of services to the health center and to the community, the technology becomes better known and therefore attracts greater public and private sector interest. This can gradually lead the community to really take over the responsibility of the long-term maintenance of the systems. Increased use of renewables in the community (e.g., in schools, small businesses, private homes, community houses) will also enable technical expertise to be developed and maintained at the village level.

A few projects have been initiated with this approach in mind. One such project is described in this guide. Much remains to be learned, however, to make this concept sustainable.

This guide is an excellent initiative, which fully contributes to the above approach. By looking at all the energy needs of rural health facilities and providing technical guidance on how these can be met with renewable energy technologies, it fills an important gap. I congratulate the authors of this guide and their sponsors. I make strong wishes for many more initiatives to be launched that will provide clean energy to meet the pressing health requirements of rural areas. Renewable energy is the energy that we must use today wherever it makes economical sense! And we can do a lot more to show that it makes sense!

\section{Michel Zaffran, Coordinator}

Quality of Immunizations Services, Expanded Programme on Immunization World Health Organization 


\section{PREFACE}

Rural health service is an important national and international priority. However, the availability of electricity to support proper rural health services is less than adequate in many countries. In recent years the development of reasonably priced and reliable energy systems has made it possible to provide vaccines and other basic health care services in remote areas. A number of international, national, and local institutions, NGOs, and private companies are now deploying renewable energy systems to rural communities in the developing world where health care in rural areas is a national priority.

Because renewable energy is regionally diverse, the appropriate renewable energy system will be regionally and site dependent. While photovoltaic (PV) systems have paved the way and are being deployed in most cases, several micro/mini renewable sources of electricity should be considered. One of the objectives of this guidebook is to expand the opportunity beyond PV to areas of good wind or hydro resources. Also, in the near future we may see micro-biomass gasification or direct combustion, as well as concentrated solar thermal-electric technologies come into play.

The three important drivers in the selection are the natural resource availability, the size and timing of the electrical loads, and the cost of the various components, including fossil fuel alternatives. This guidebook provides the considerations and some comparisons in the selection of alternative renewable and hybrid systems for health clinics.

The National Renewable Energy Laboratory's (NREL) Village Power Program has commissioned this guidebook to help communicate the appropriate role of renewables in providing rural health care services. The two primary authors, Tony Jimenez and Ken Olson, combine the technical analysis and practical design, deployment, and training experience that has made them such an effective team. It is our intention that this guidebook will be useful to several audiences in their consideration of renewables as a serious option for electrifying rural health clinics. It may be useful as well to renewable energy practitioners in defining the parameters for designing and deploying their products for health clinic needs.

This is the first in a series of rural applications guidebooks that NREL's Village Power Program is commissioning to couple commercial renewable systems with rural applications, including water, rural schools, and micro-enterprise. The guidebooks are complemented by NREL's Village Power Program's development activities, international pilot projects, and visiting professionals program. For more information on NREL's Village Power Program, please contact our web site, http://www.rsvp.nrel.gov/rsvp/.

Larry Flowers

Team Leader, International Projects

National Renewable Energy Laboratory 


\section{CONTENTS}

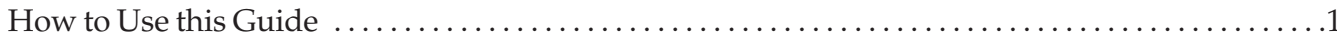

Introduction: The Need for Primary Health Care $\ldots \ldots \ldots \ldots \ldots \ldots \ldots \ldots \ldots \ldots \ldots \ldots \ldots \ldots \ldots \ldots \ldots \ldots \ldots$

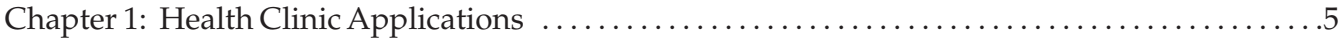

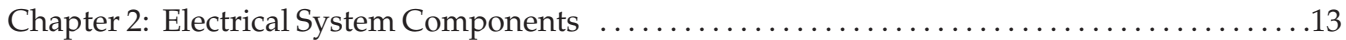

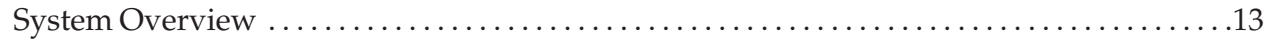

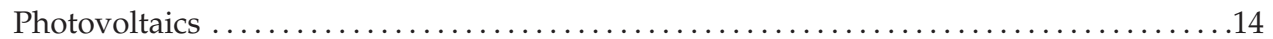

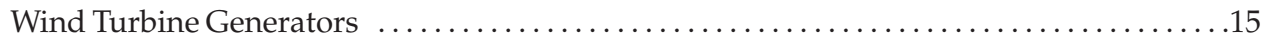

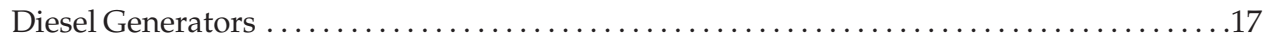

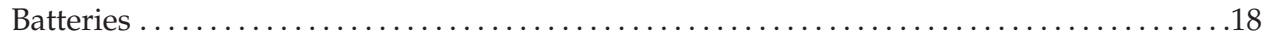

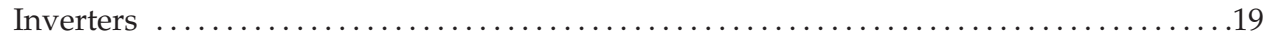

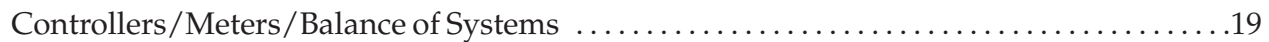

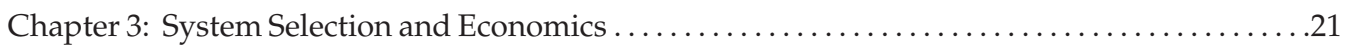

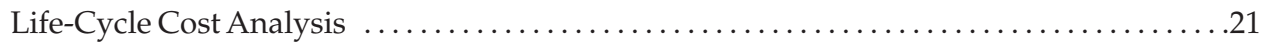

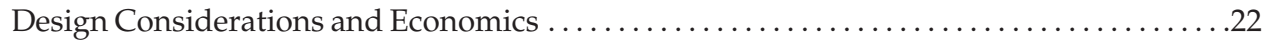

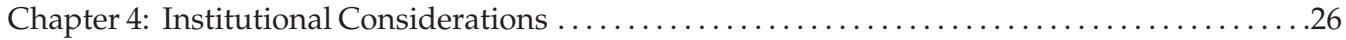

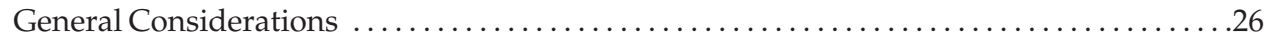

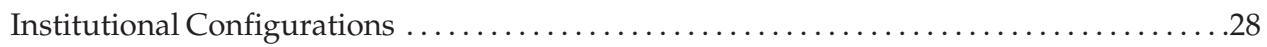

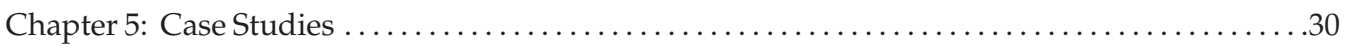

$\# 1$-Photovoltaics for Immunization: Experience in Africa $\ldots \ldots \ldots \ldots \ldots \ldots \ldots \ldots \ldots \ldots \ldots \ldots \ldots \ldots \ldots$

\#2-Photovoltaic Powered Health Clinic: Chihuahua, Mexico . . . . . . . . . . . . . . . . . 32

\#3-300 Photovoltaic Powered Health Clinics: Peru's National Program . . . . . . . . . . . . 33

\#4-Photovoltaics for Health: An Integrated Approach $\ldots \ldots \ldots \ldots \ldots \ldots \ldots \ldots \ldots \ldots \ldots \ldots \ldots$

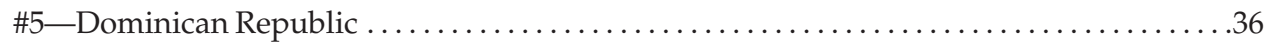

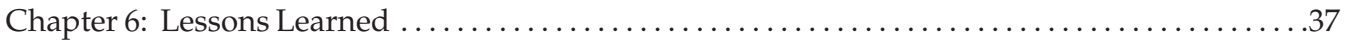

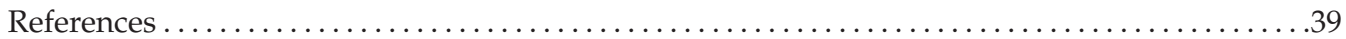

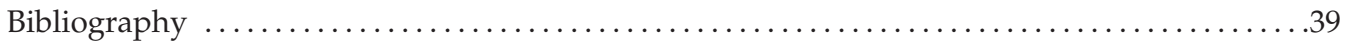

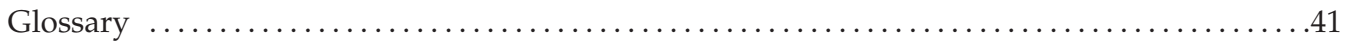

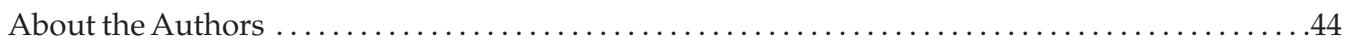




\section{HOW TO USE THIS GUIDE}

\section{Who is this Guide for?}

While containing useful information for anyone interested in health clinic electrification, this Guide is written primarily for decision-makers within government ministries or private agencies that are involved or interested in health clinic electrification using renewable energy (RE) technologies.

\section{What is the Purpose of this Guide?}

The purpose of this guide is to give the reader a broad understanding of the technical, social, and organizational aspects of health clinic electrification. The authors' goal is to help readers to accurately assess their health clinic's electrical needs, select appropriate and cost-effective technologies to meet those needs, and lastly, to put into place an effective infrastructure to install and maintain the hardware.

\section{What is in this Guide?}

This Guide gives a broad overview of health clinic electrification with an emphasis on the use of RE. The use of solar thermal technologies to meet various heating applications is briefly discussed. Chapter 1 discusses typical health clinic electrical applications, such as refrigeration, lighting, and communications. Information on typical power draws and duty cycles for each type of equipment is given as well. Chapter 2 discusses the components of stand-alone power systems. For each component there is a description of how it works, its cost, lifetime, proper operation and maintenance, and limitations. The first section of Chapter 3 gives an overview of life-cycle cost analysis. The remainder of the chapter is devoted to discussing the various factors that influence the design of stand-alone RE systems for a particular location. Chapter 4 explores the various social and institutional issues that need to be addressed in order to have a successful health clinic electrification program. There is some emphasis in this chapter towards large-scale projects done by governments or large private agencies, but much of the content, especially that relating to maintenance, user training, and project sustainability will be of interest to a wider audience. Chapter 5 details five health clinic electrification Case Studies. Chapter 6 gives general Lessons Learned that can be applied to future projects. These are followed by a list of references, the bibliography, and a glossary of terms used throughout this Guide. 


\section{INTRODUCTION: \\ THE NEED FOR PRIMARY HEALTH CARE}

"Not until the creation and maintenance of decent conditions of life for all people are recognized and accepted as a common obligation of all people and all countriesnot until then shall we, with a certain degree of justification, be able to speak of mankind as civilized."

Albert Einstein 1945
Health care in developing countries depends greatly upon support and administration by national governments, charitable human services, non-governmental agencies, and religious organizations. These efforts are supplemented by international aid. Through the efforts of these organizations, health distribution systems are tasked with providing medical supplies, health services, and medical staff. The needs are immense, and the efforts are often severely under-supplied and ill-equipped, particularly in remote and distant communities.

The relationship between health and energy is compelling. The World Health Organization (WHO) states that "Health and energy are interdependent factors which largely determine the progress of rural develop-

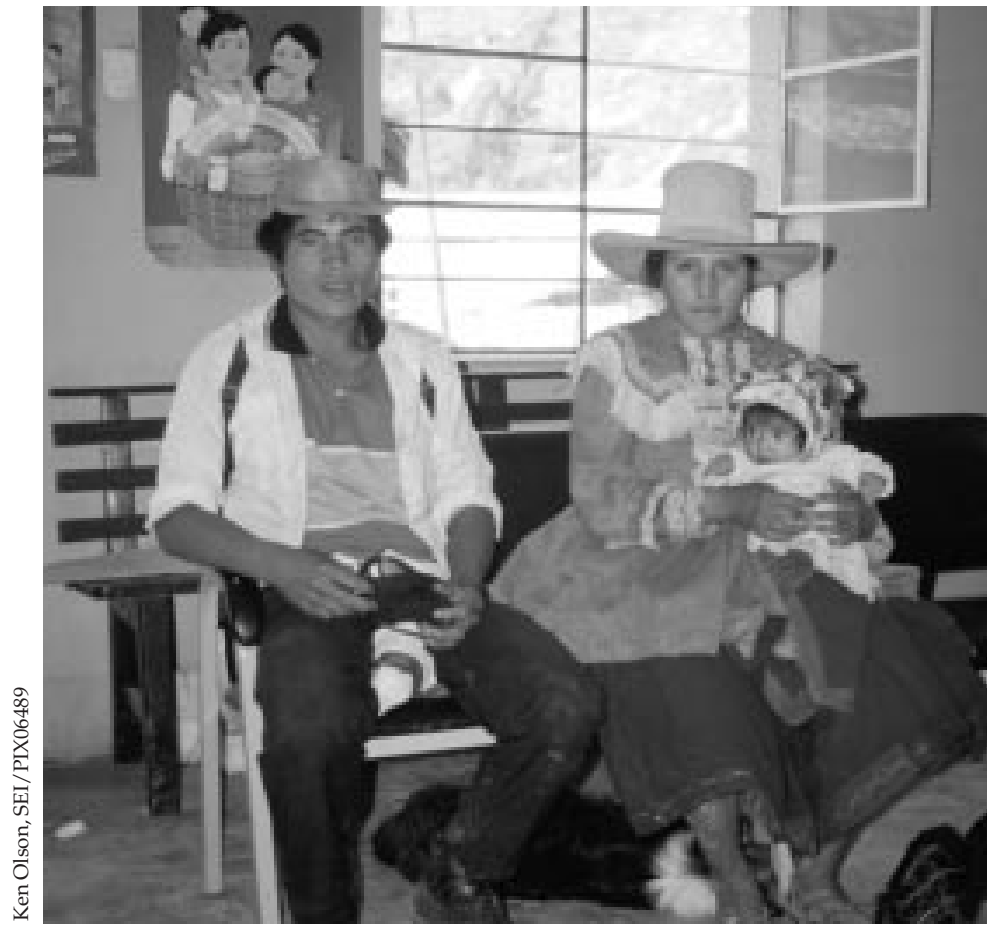
ment. ...An energy strategy for rural areas will be critical in achieving lasting health improvements....WHO believes solar energy can play an important role in improving health energy infrastructure if integrated with a broader array of end uses." 1

Primary health care programs are essential to the improvement of child survival programs and the overall quality of the human condition. Distribution of energy by conventional means has failed to be reliable or affordable in meeting the modest needs of rural health clinics in many developing countries. Supplies of

Figure I.1. A family awaits medical attention at Clinica El Pallar, near Huamachuco, Peru. 


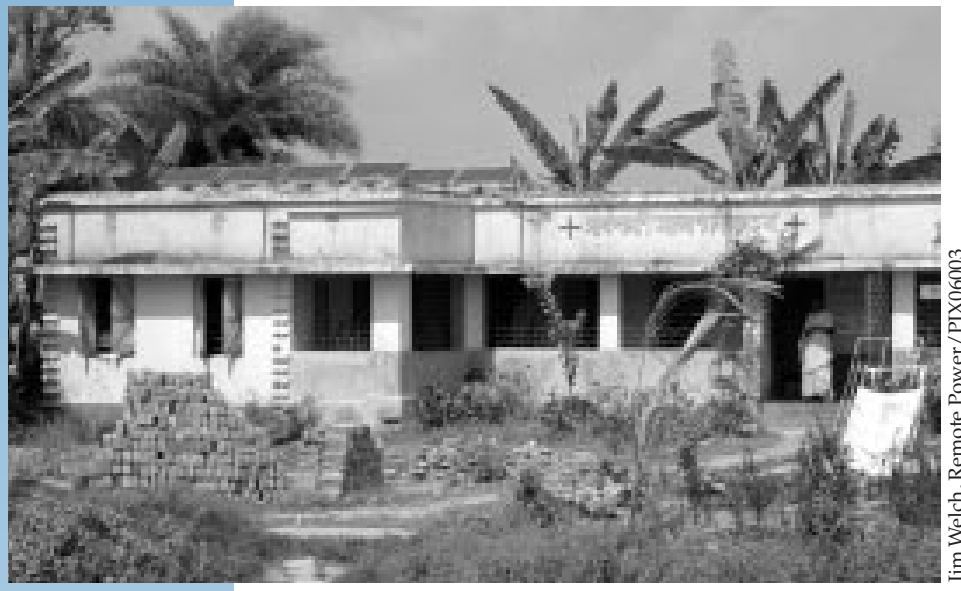

Figure I.2. Photovoltaic modules supply electricity to a local clinic in West Bengal, India.

gas and kerosene are often costly and unreliable. These fuels provide poor quality light. Propane fueled refrigerators provide adequate vaccine preservation, but the more widely used kerosene fueled refrigerators do not. Gasoline and diesel fuels can power motor generators for electrical service, but these generators are often nonfunctional, always expensive, and usually reserved for emergencies when available. Most rural health clinics in developing areas are without electrical power.

Renewable energy from sun and wind is an abundant and ubiquitous resource. Although capable of providing plentiful and reliable electricity, these resources are largely untapped. Reliable electricity produced on site has proven capable of delivering high quality electricity for vaccine refrigeration, lighting, communication, medical appliances, clean water supplies, and sanitation. It can also improve management, logistics, distribution of information, education, and communication. In locations where it is difficult to keep trained medical staff in the field, reliable electricity can provide highly valued life-style amenities such as light, music, and broadcast communications. There are successful examples of electrified health clinics that generate operating income to assist financial selfsupport. (See Case Studies, Chapter 5.)
International policy regarding rural health is evolving toward decentralization of services and more comprehensive strategies. Primary Health Care (PHC) has selectively focussed on child survival programs such as immunization and oral rehydration therapy. ${ }^{2}$ A more comprehensive approach is evolving that extends beyond the walls of the health clinic to encompass the broader aspects of community health. Comprehensive PHC includes such items as the provision of clean water supplies and the promotion of health education. Partnerships with other sectors of human service including education, agriculture, and economic development are desirable, especially where funds are limited.

\section{World Health Facts}

1. Of over 52 million deaths in 1996 , over 40 million were in developing countries, including almost 9 million in the least developed countries.

2. In 1995, 5 million babies born in developing countries died in the first month of life

3. Infectious and parasitic diseases accounted for $43 \%$ of the 40 million deaths in developing countries.

4. The leading killer among infectious diseases in 1996 was acute lower respiratory infection which killed 3.9 million people. Deaths due to other infectious diseases in 1996 were as follows:

Tuberculosis (3 million),

Diarrhea (2.5 million), Malaria (2.5 million), HIV / AIDS (1.5 million).

5. The percentage of coverage of children immunized against six major childhood diseases increased from 5\% in 1974 to $80 \%$ in 1995.

6. More than 120 million children under five in India were immunized against poliomyelitis in a single day in 1996.

(from "Fifty Facts from the World Health Report 1997") 3 


\section{What is a Health Clinic?}

In this Guide the term "health clinic" is used as a catch-all term referring to many types of health facilities in a varying range of sizes. At the small end, this ranges down to what may be termed a "health post." This is typically a one- or two-room facility that may or may not be wholly dedicated to providing health services. There is usually no permanent doctor or nurse present. A doctor or nurse may visit periodically. In addition to the itinerant nurse or doctor, the facility may have a full- or part-time primary health worker. 4 Services available at health posts include the treatment of minor illnesses, and the tending of minor injuries. Patients with more serious problems are referred to the local district hospital. In general, these facilities have only the most basic items, communications equipment, lights, and occasionally, a vaccine refrigerator.

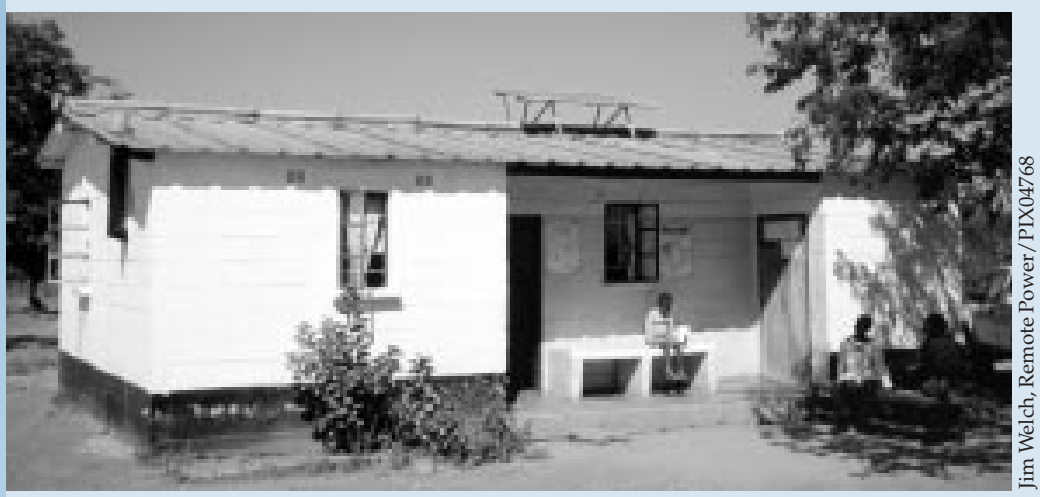

Figure I.3. Photovoltaic system supplies power for a vaccine refrigerator and lights at a health clinic in Zambia.

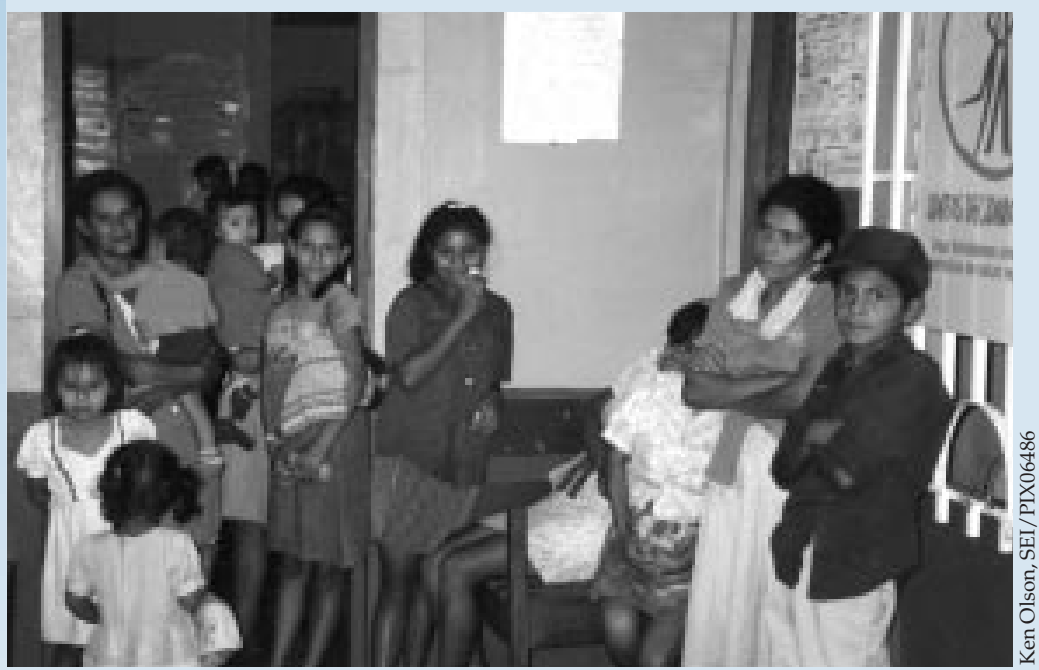

Figure 1.4. Patients seek the most basic of primary health care services at Clinica San Martin near Matagalpa, Nicaragua.
A step up from the health post is the "health clinic" with a somewhat larger facility and a greater likelihood of having a full-time nurse(s). A health clinic offers a wider array of services than a health post. Some health clinics may have one or two beds for the more seriously ill or injured. These facilities are more likely than health posts to have items such as vaccine refrigerators, and may have some simple laboratory equipment such as centrifuges and microscopes. Additional power loads may include lighting and a TV / VCR for the staff quarters.

At the large end of the health clinic continuum are small rural hospitals with a dozen to several dozen beds. In many developing countries, this is the lowest level facility permanently staffed with doctors. Along with the doctors are supporting staff such as nurses, nurse's aides, and maintenance workers. Hospitals normally offer services such as surgery, rehabilitation, and laboratory and radiological services. 


\section{CHAPTER 1: HEALTH CLINIC APPLICATIONS}

\section{Chapter Introduction}

The most common applications needed at rural health care facilities require some form of energy. This chapter describes the most common health clinic applications. The tables in this chapter give typical power requirements and duty cycles for each application. Study of this chapter will help the reader to identify the most critical applications for a particular health clinic.

\section{Vaccine Refrigeration and Ice Pack Freezing}

Immunization programs depend upon reliable refrigeration to preserve vaccines to prevent or eradicate dangerous diseases including Polio, Diptheria, Tetanus, Pertussis, Tuberculosis,
Measles, Yellow Fever, and Hepatitus B. The Cold Chain is a system of people and equipment present in almost all countries that attempts to keep vaccines at proper temperatures as they are distributed from the manufacturer to the locations where they are administered. Fail safe refrigeration within a specified range of temperature, from point-of-manufacture to point-ofuse, is critical to the mission of the Cold Chain.

At district and rural health centers vaccines are stored for up to one month and require a stable temperature between $0^{\circ} \mathrm{C}\left(32^{\circ} \mathrm{F}\right)$ and $8^{\circ} \mathrm{C}$ $\left(46^{\circ} \mathrm{F}\right)$. Once the vaccines have been exposed to temperatures outside this range, potency is forever lost. It is not apparent to the health worker that a vaccine has been rendered impotent because of heat exposure without reliable indicators or complete laboratory tests.

The most remote health clinic in this logistical supply chain must also be able to freeze ice packets to carry the vaccines in coolers to surrounding sites served by the health clinic. These sites can be up to several days travel away, by foot or mule, from the last health clinic in the Cold Chain. Compression refrigeration, which requires electricity, offers the most stable temperature control for vaccines and the capacity for ice making.

Absorption refrigeration, fueled by propane or kerosene, is common at unelectrified health clinics. Absorption refrigerators are vulnerable to interruption of their fuel supply resulting in the loss of vaccines. Kerosenefueled refrigerators cannot maintain vaccines adequately, because the temperature is not thermostatically controlled. Kerosene-fueled refrigeration requires frequent manual adjustment to the

Figure 1.1. Health clinic showing typical applications. 


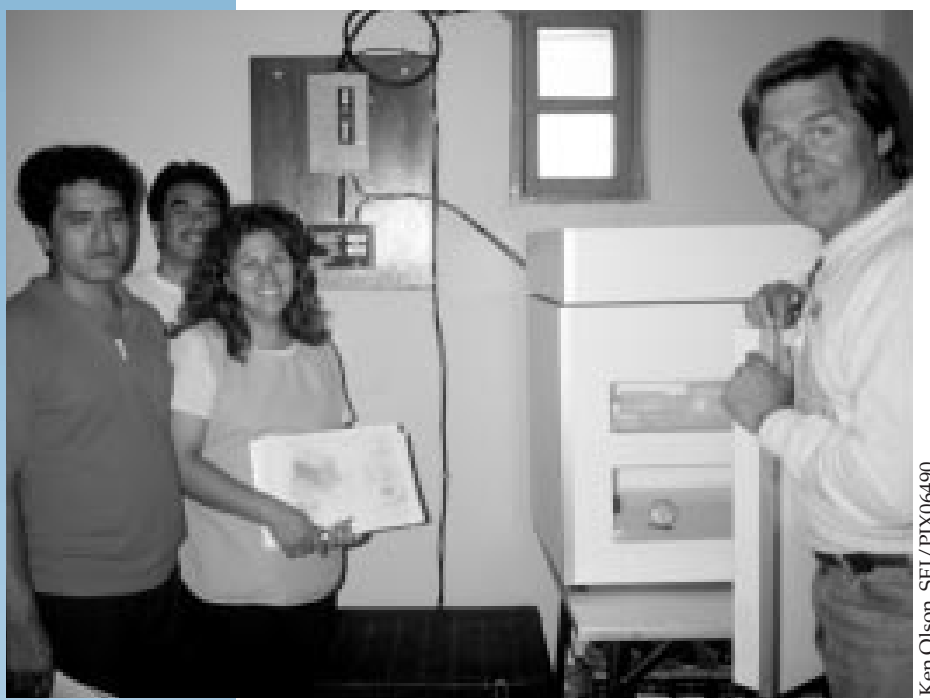

Figure 1.2. Health care staff receive training in operation of their new photovoltaic powered vaccine refrigerator at Clinica El Molino, near Trujillo, Peru.

\section{Table 1.1. Power Consumption for Lighting}

$\begin{array}{lcccc}\text { Lamp type } & \begin{array}{c}\text { Rated } \\ \text { watts }\end{array} & \begin{array}{c}\text { Light output } \\ \text { lumens } \\ \text { Candle }\end{array} & \begin{array}{c}\text { Efficiency } \\ \text { lumens/watt }\end{array} & \begin{array}{c}\text { Lifetime } \\ \text { hrs }\end{array} \\ \text { Kerosene lamp } & & 10-100 & & \\ \text { Incandescent bulb } & 15 & 135 & 9 & 850 \\ & 25 & 225 & 9 & 850 \\ \text { Halogen bulb } & 100 & 900 & 9 & 850 \\ & 10 & 140 & 14 & 2,000 \\ \text { Fluorescent tube } & 20 & 350 & 18 & 2,000 \\ & 8 & 400 & 40 & 5,000 \\ & 13 & 715 & 40 & 5,000 \\ \text { Compact fluorescent } & 15 & 1250 & 54 & 7,500 \\ & 18 & 940 & 72 & 10,000 \\ & 27 & 1,100 & 66 & 10,000 \\ & 15 & & 66 & 10,000\end{array}$

flame as ambient air temperatures vary from day to night. Less common than kerosene-fueled refrigerators, propane-fueled refrigerators do have adequate temperature regulation. In locations with a reliable fuel supply, it may not be worthwhile to replace propane-fueled refrigerators with compression refrigerators.

Solar and wind energy generated on site can power compression-type refrigerators and icepack freezers. Temperature control is far more accurate than with kerosene-fueled absorption refrigeration. Many Cold Chain programs use renewable energy to power efficient compression refrigerators at remote locations where the supply of kerosene and propane is unreliable or costly. Because most often a PV system powers these refrigerators they are often referred to as "PV refrigerators" even though they can be powered from any electrical source. Efficient compression-type refrigerators can be powered by 12 or $24 \mathrm{~V}$ (volt) storage batteries which are recharged on site by photovoltaic panels or a small wind turbine. The main advantage is greater temperature control and elimination of the need for a fuel supply.

\section{Lighting}

Electricity offers a quality of light to which gas or kerosene cannot compare. Kerosene lighting is most common in unelectrified communities. Kerosene is a known safety hazard and contributes to poor indoor air quality as well. Electric light greatly improves emergency treatment, birthing, maternity care, surgery, administrative tasks, and other medical functions. Outdoor light makes the health clinic more accessible at night. In unelectrified communities, a health clinic with light becomes a strong community focus.

When using a renewable energy system, energy efficiency is key to reliability and affordability. A dollar spent on efficiency will generally save many dollars in total system costs. Table 1.1. shows the energy consumed and light produced for incandescent and fluorescent lights, as compared to candles and kerosene. It is easy to see that the electric light is far superior in terms of quantity and quality of light. Compact fluorescent lights give four times the light per watt consumed, as compared to incandescent bulbs. With 
an expected service life of 10,000 hours, they last ten times longer than incandescent bulbs.

\section{Communications}

Radio and radiotelephone communications will greatly improve health care services at rural health clinics. Emergency medical treatment is greatly facilitated with reliable communications to other health clinics and facilities in the region. Doctors and nurses must often cover numerous communities in a region and have scheduled days to visit each community. Health care services can be greatly improved by full-time communications with itinerant medical staff or regional facilities. Communications are also essential to routine operation and management functions including procurement of supplies, surveillance and reporting on disease and immunization, and assistance with diagnosis of illness and medical procedures

Health clinic communications require very little electrical energy. Stand-by power consumption may be as little as 2 watts (W). Power consumption for transmitting and receiving are higher, on the order of 30-100 W, but generally are for very little time. Many rural health clinics

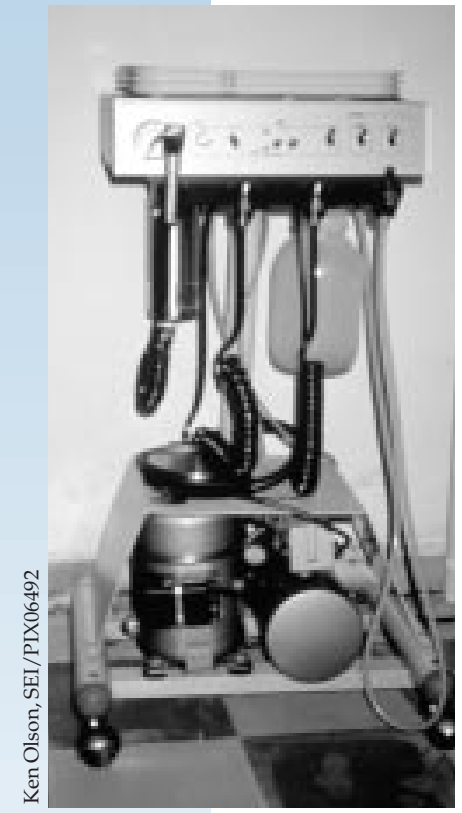
have reliable two-way regional communication via $\mathrm{VHF}$ radio with electricity provided by a single 30-W PV module.

\section{Medical Appliances}

Small medical appliances that operate on 120-volt (V) AC electricity may be operated if an inverter is incorporated into the system. Health clinics can make use of a microscope, a nebulizer,

Figure 1.5. An RE system can power a small dental care unit used to provide preventative dental care. Most clinics with access to a dentist serve primarily to pull teeth.

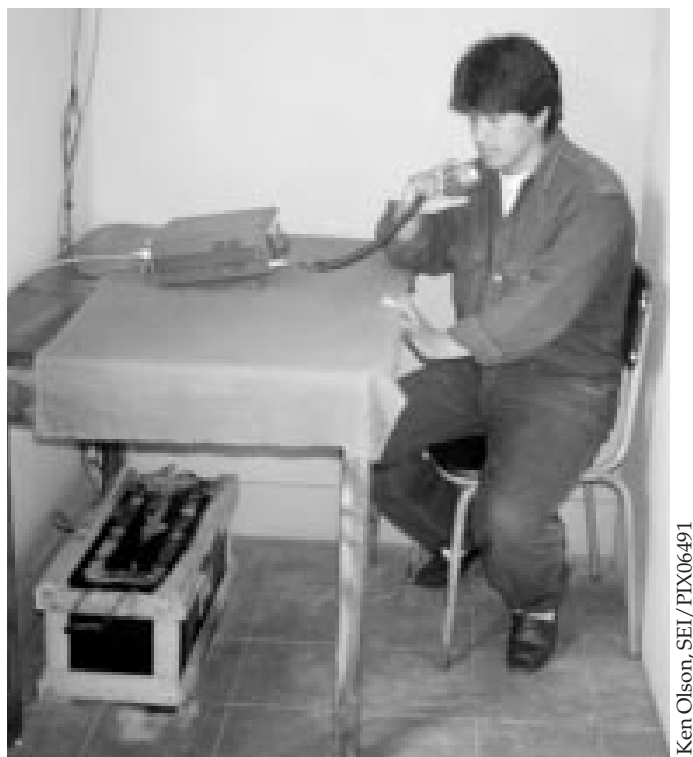

Figure 1.3. A PV powered radio is used by health staff at Clinica El Pallar to request technical or logistical assistance and to report on significant health risks in the region.

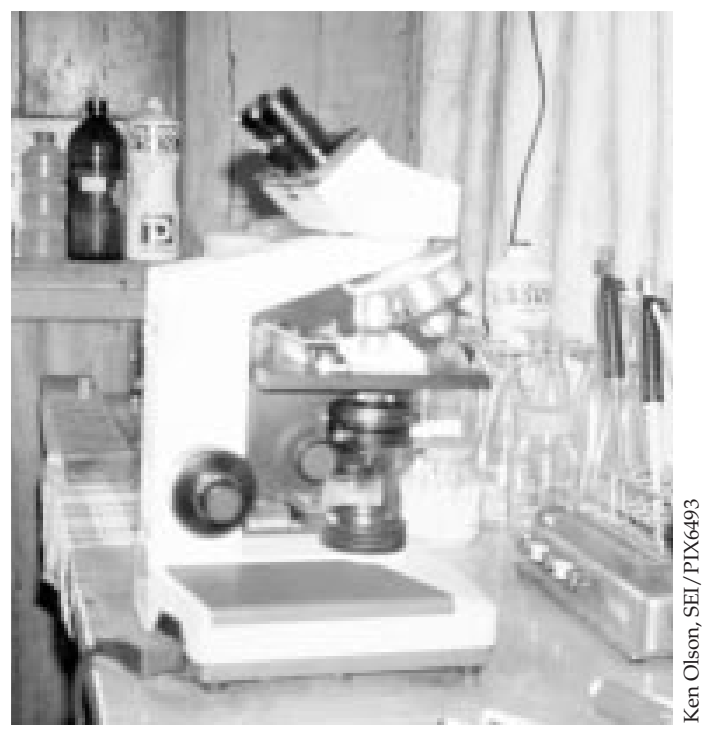

Figure 1.4. A small laboratory microscope requires only moderate use of a 30 watt light. It is essential equipment for diagnosis in the field.

a centrifuge, dental equipment, and other medical appliances. 


\section{Sterilization}

Sterilization requires rather high temperatures, approximately $120^{\circ} \mathrm{C}\left(250^{\circ} \mathrm{F}\right)$. Although photovoltaic systems are able to power electric autoclaves with the use of an inverter, the power consumption is quite high and economically impractical. It is generally more appropriate to sterilize with thermal energy rather than electricity. These temperatures can be produced by solar thermal collector systems at a lower cost, especially in areas with good solar insolation.

\section{Water Treatment}

Perhaps one of the most common and serious health concerns in less developed countries is readily accessible clean drinking water. WHO estimates that water-bred illnesses are responsible for 50,000 deaths daily. 5 WHO also estimates that $80 \%$ of illnesses worldwide are transmitted by contaminated water. Water contamination may be particulate, microbiological, chemical, or parasitic.

Common means of chemical disinfection include chlorine and iodine, both of which pro-

Human consumption: 5-10 liters/day

Personal hygiene: 20-50 liters/day per person required for washing utensils, food, clothes, and bathing. duce an objectionable taste and odor. The greatest advantage of using chlorine is the residual effect it maintains throughout a distribution system. A $2 \%$ tincture of iodine can purify small amounts of water from bacterial content.

There are a number of low-cost, non-electrical means of treating water to make it safe for human consumption.

There are more sophisticated means of water treatment that generate higher volumes of potable water and are effective for a wider variety of types of contamination. These processes require electricity that can be produced on site with solar and wind power. They include ozone treatment, reverse osmosis, photochemical, also known as ultraviolet or UV, disinfection and carbon filters. Some processes utilize a combination of these treatments. There are also several technologies that provide for on-site production of disinfectants such as sodium hypochlorite from a water and salt solution.

Ozone is a highly activated form of oxygen often used in combination with activated carbon filters to disinfect water supplies. It adds no taste or odor to the water. It does not offer residual disinfection over time. Ozone treatment has low electrical power requirements. The process is very suitable to solar or wind generated power as it requires only $0.3 \mathrm{~W}$-hours (Wh) per liter.

Activated carbon can remove chloroform, industrial chemicals, and heavy metals from drinking water. The filter must be replaced periodically to prevent bacterial contamination.

UV disinfection requires only a small amount of electricity ( $0.2 \mathrm{Wh}$ per liter) and is effective at killing micro-organisms. Yet, organisms such as Giardia are immune to UV radiation.

\section{Water Supply}

Surface water from sources such as lakes and streams is most prone to contamination. Handdug shallow wells work better if lined, covered, and provided with adequate drainage at the site. These shallow wells should be equipped with a means of pumping the water so as not to introduce contamination from the vessels used to draw water. Deep wells generally provide higher quality water, but require an energy source for pumping significant volumes. Power requirements increase with the volume of water required and the depth from which it must be pumped. Solar or wind power (or both) generated on site can economically meet the broad range of needs between manual pumps and large-motor generator driven pumps. 


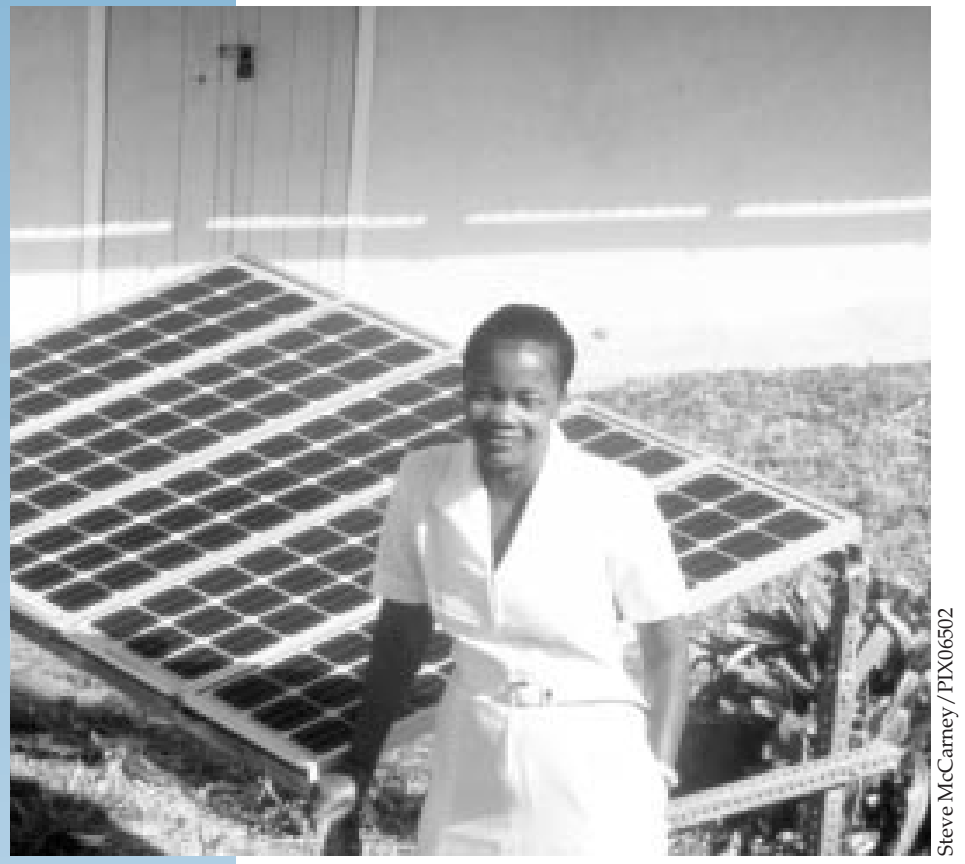

Figure 1.6. Unelectrifed rural communities have difficulty keeping trained medical staff at health clinics. Modest life style amenities such as lighting, music, and broadcast communications are important to the retention of staff at rural health clinics.

\section{Education}

Providing lighting for educational activities enhances health education. Audio-visual equipment requires modest amounts of electrical energy and can be powered by an RE system.

\section{Health Staff Amenities}

Quality-of-living conditions for health staff is an important factor in quality of health services. Professionally trained doctors and nurses are accustomed to a quality of life that necessitates electricity. The lack of these basic amenities of lighting and broadcast communications in rural areas of under-developed countries is a major deterrent to retaining trained health care staff in the community.

\section{Income Generation}

Health care in developing countries is a social service that is often under-funded. Rural health clinics lack the operating funds for supplies and equipment maintenance.

Pilot projects at rural health clinics in various countries have proven successful at generating operating income with the use of renewable energy systems. Video theaters and battery charging services powered with solar electricity have generated significant funds within communities to partially support the operating expenses of rural health clinics. Case Study \#4 describes four such communities in Colombia, South America (see page 34).

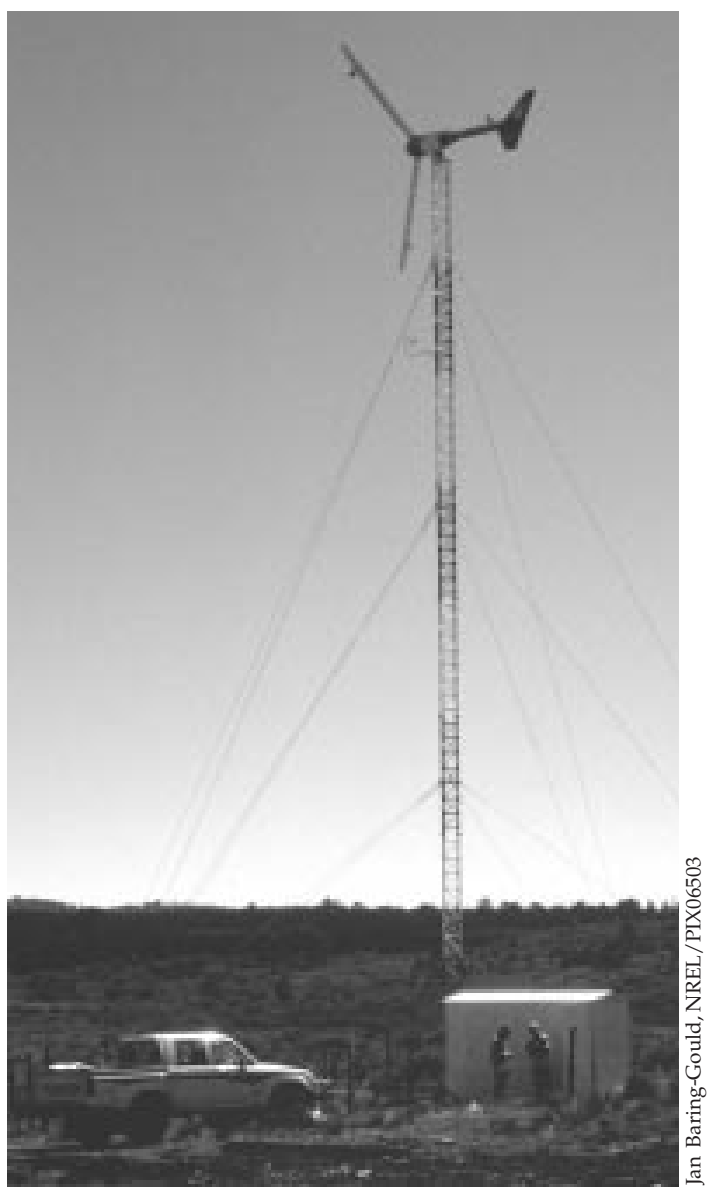

Figure 1.7. A wind turbine supplies electricity to a health clinic (not shown) and the surrounding village of Villa Las Araucarias, Chile. 


\section{Table 1.2. Power and Energy Consumption for Medical Appliances}

$\begin{array}{lccc}\text { Vaccine refrigerator } & \begin{array}{c}\text { Power } \\ \text { (watts) }\end{array} & \begin{array}{c}\text { On-time } \\ \text { (hours/day) }\end{array} & \begin{array}{c}\text { Energy/day } \\ \text { (watt-hours) }\end{array} \\ \text { Vaccine refrigerator/freezer } & 60 & 5-10 & 300-600 \\ \text { Lights (each) } & 60 & 6-12 & 410-720 \\ \text { Communication VHF radio } & 20 & 2-12 & 40-240 \\ \quad \text { Stand-by } & 2 & 12 & 24 \\ \quad \text { Transmitting } & 30 & 1 & 30 \\ \text { Microscope } & 15 & 1.0 & 15 \\ \text { Centrifuge nebulizer } & 150 & 0.3-2.0 & 50-300 \\ \text { Vaporizer } & 40 & 1.0-4.0 & 40-160 \\ \text { Oxygen concentrator } & 300 & 1.0-4.0 & 300-1200 \\ \text { Overhead fan } & 40 & 4-12 & 160-480 \\ \text { Water pump (1500 liters/day } & 100 & 6 & 600 \\ \text { from 40 meters) } & & & 15-60 \\ \text { TV } & & 1.0-4.0 & 60-240 \\ \quad \text { 12" B\&W } & 15 & 1.0-4.0 & 130-520 \\ \text { 19" Color } & 60 & 1.0-4.0 & 30-120 \\ \quad 25 " \text { Color } & 130 & 1.0-4.0 & 150-3000 \\ \text { VCR } & 30 & 1.0-12 & \\ \text { AM/FM stereo } & 15 & 0.5-2.0 & \\ \text { Electric sterilizer* } & 1500 & & \end{array}$

* Thermal sterilization should be used unless the electrical power system can handle the high power and energy requirements of an electric sterilizer.

\section{Community Center}

The health clinic may be the only electrified building in a given village. Being well-lit, it becomes a magnet for after hours activities such as night education classes and serves as a community center. Accounting for this in the design of the system will increase the benefits of the system to the community and lead to greater community support and "buy in."

\section{Centerpiece of a Village Mini-Grid}

In some locations where greater resources are available, a larger power system may be installed that is used to electrify other nearby buildings in addition to the local health clinic. 


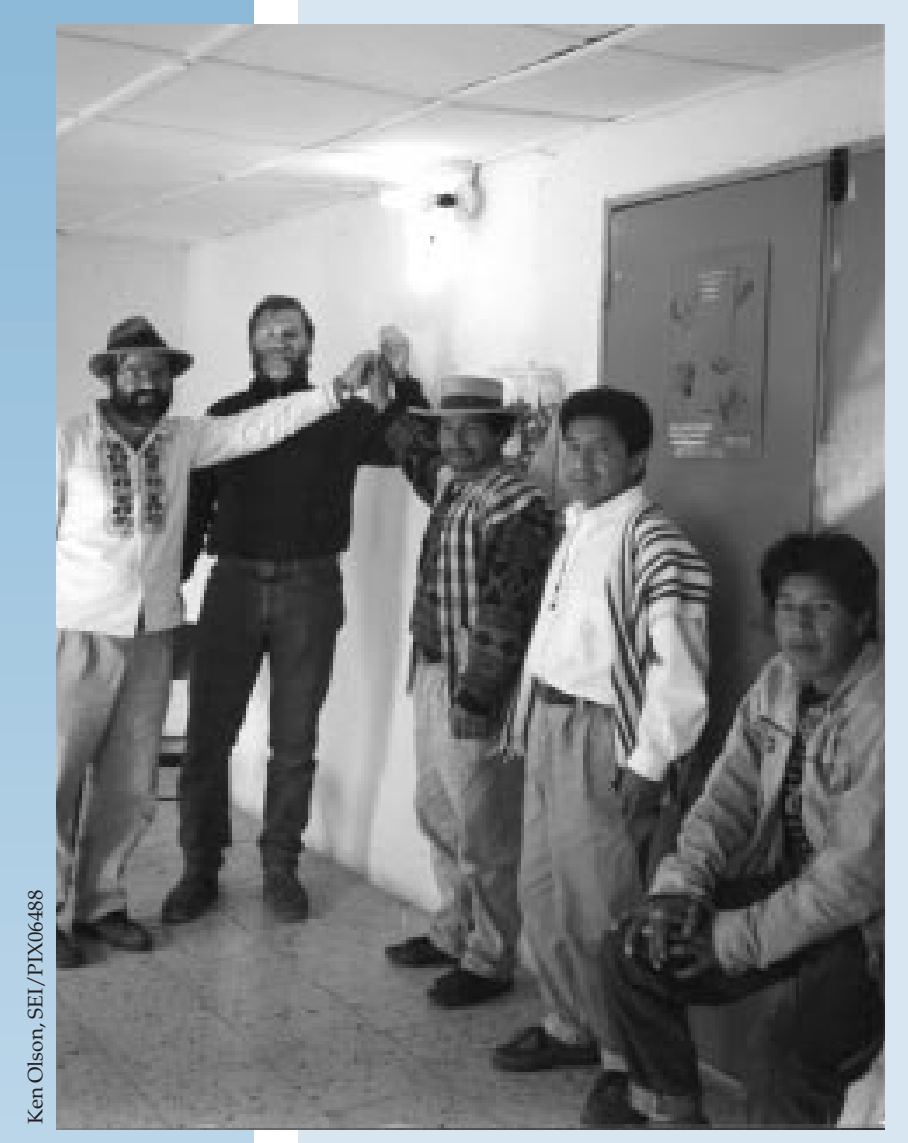

Figure 1.8. Leaders of the Paez Indian Community inaugurate a photovoltaic lighting system in Mosoco, a community of the Tierradentro region of southern Colombia.

\section{Community Lighting Tierradentro, Colombia}

In October of 1992, a solar powered lighting system was installed at the Community Health Center in Mosoco, a community of Paez Indians in the rugged mountainous region of southern Colombia called Tierradentro (which means "the land within"). The health center became the only electrified building in the community with the exception of the Catholic church which had a small gasoline generator operated only two hours each evening.

The health center lighting system came to serve many more purposes than health care. Shortly after the installation, the Paez community used the center to translate the Colombian National Constitution into their native language. Adult literacy classes and agricultural education were also carried out under the brilliance of a PV powered light during the evening. The usefulness of the lighting system did not stop there though!

In June of 1995, the region of Tierradentro experienced heavy rains and a massive earthquake which resulted in many landslides. Three communities were entirely lost under the deluge of mud and rock. Thousands lost their lives and many survivors were left homeless. All roads to the region were blocked by the landslides.

In the community of Mosoco, only one building was left standing - the health center. The PV lighting system was the only electrical power available in the entire region. The Health Center was used by the Red Cross, the Colombian Army, and other organizations providing disaster relief services to the people of Tierradentro. 


\section{Solar Thermal Applications}

Solar thermal technologies are used for applications that require energy for heating rather than electricity. Solar thermal energy is used to heat air or water by means of a dark surface under glass or similar transparent material. Temperatures may regularly reach $93^{\circ} \mathrm{C}-177^{\circ} \mathrm{C}\left(200^{\circ} \mathrm{F}-350^{\circ} \mathrm{F}\right)$. The higher end of this temperature range may be achieved by use of insulation or reflectors or both. Applications that make use of solar thermal energy include water heating, cooking, pasteurization, and water distillation.

Much higher temperatures, on the order of $204^{\circ} \mathrm{C}-316^{\circ} \mathrm{C}\left(400^{\circ} \mathrm{F}-600^{\circ} \mathrm{F}\right)$, may be attained by concentrating sunlight on a small area. Solar steam sterilization units make use of reflectors, evacuated glass tubes, and selective surfaces. The reflectors increase the level of sunlight into the unit. The evacuated tube acts like a thermos bottle to reduce heat loss by conduction. The selective surface in the collector reduces the heat loss caused by thermal radiation.

\section{Solar Water Heating}

Water is easily heated by the sun. The simplest ways are by running water through a length of black tubing or placing a tank of water outside on a sunny day. Water temperatures may become warm to hot depending upon the amount of sunlight, temperature of the ambient air, and the insulation around the storage tank. Higher temperatures may be achieved by covering the dark surface with glass or similar transparent material.

Solar flat-plate collectors can be used to pasteurize water. These collectors consist of a black absorber plate in an insulated box covered by a sheet of tempered glass. Water is circulated through the collector for heating and then pumped to a storage tank.

\section{Solar Water Distillation and Pasteurization}

Simple solar thermal technologies, such as pasteurization and distillation, are effective for treating small quantities of biologically contaminated water. These are good alternatives to boiling water. Although boiling water for five minutes or more kills bacteria, it is often overlooked because of the inconvenience, use of fuel, and the small volume yield.

Water or milk may be pasteurized by heating it to $65^{\circ} \mathrm{C}\left(150^{\circ} \mathrm{F}\right)$ for 30 minutes or $71^{\circ} \mathrm{C}\left(161^{\circ} \mathrm{F}\right)$ for 15 seconds. Pasteurization disinfects microbiologically contaminated water by killing viruses, bacteria, and protozoans. However, it will not eliminate chemical pollutants.

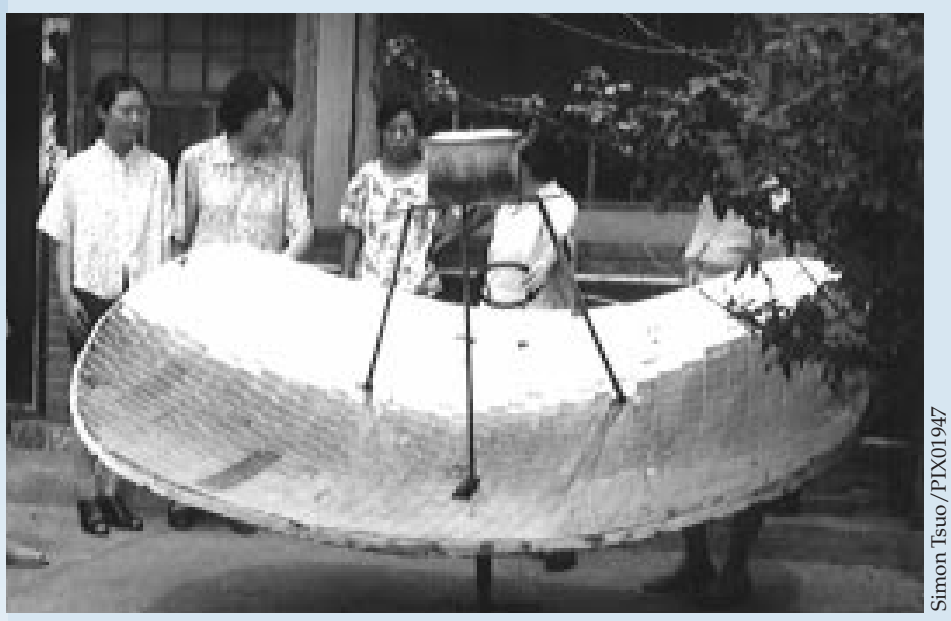

Figure 1.9. Chinese women use a solar cooker to heat water.
Solar pasteurization may be achieved by placing water or milk containers in a solar cooker-an insulated box covered with glass. Reflectors increase the amount of sunlight directed into the box. Temperatures sufficient for pasteurization are easily achieved in this manner.

Solar distillation is a process where water is heated to form steam and then it condenses back to water. Distillation will remove bacterial, viral, and chemical contaminants from brackish or salt water making it drinkable. A solar distiller looks similar to a solar cooker and will produce about 3-4 liters/day $/ \mathrm{m}^{2}$ of absorber surface. 


\section{CHAPTER 2: ELECTRICAL SYSTEM COMPONENTS}

\section{Chapter Introduction}

This chapter gives an overview of the main components typically used in renewable energy systems. Diesel and gasoline engine generators are also discussed. For each item, the discussion includes how it works, proper use, cost, lifetime, and limitations.

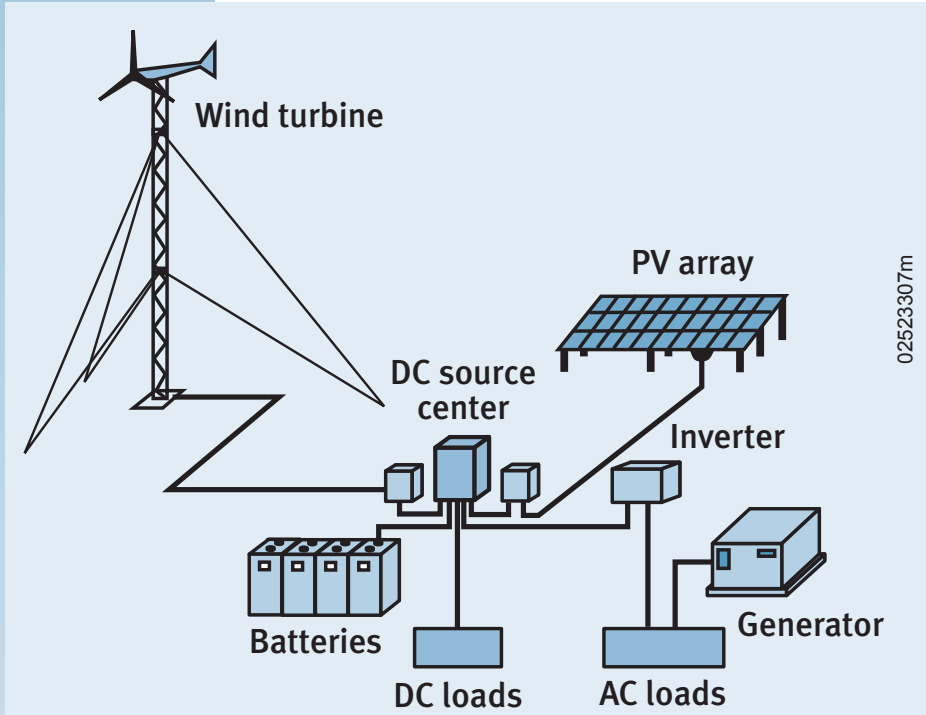

Wind/PV/Diesel Hybrid System

Figure 2.1. Hybrid System Configuration: Generalized hybrid system configuration showing energy storage components (photovoltaic, wind turbine, and generator), energy storage components (batteries), energy conversion components (inverter), and balance of system components (direct current source center and charge controller). Courtesy of Bergey Wind Company

\section{System Overview}

\section{Introduction}

A hybrid system comprises components that produce, store, and deliver electricity to the application. Figure 2.1. shows a schematic of a hybrid system. Not all systems have all the components shown. In general, PV panels, small wind turbines, and batteries are all DC devices. If $\mathrm{AC}$ power is desired, the DC power must be converted to AC. Generators normally produce AC power, but some models also produce DC power. The components of a hybrid system fall into one of four categories.

\section{Energy Generation}

Wind turbines and engines use generators to convert mechanical motion into electricity. PV panels convert sunlight directly into electricity.

\section{Energy Storage}

These devices store energy and release it when it is needed. Energy storage often improves both the performance and economics of the system. The most common energy storage device used in hybrid systems is the battery.

\section{Energy Conversion}

In hybrid systems, energy conversion refers to converting AC electricity to DC or vice versa. A variety of equipment can be used to do this. Inverters convert DC to AC. Rectifiers convert $\mathrm{AC}$ to DC. Bi-directional inverters combine the functions of both inverters and rectifiers.

\section{Balance of System (BOS)}

BOS items include monitoring equipment, a dump load (a device that sheds excess energy produced by the system), and the wiring and hardware needed to complete the system. 


\section{Photovoltaics}

\section{Introduction}

PV panels convert sunlight directly into DC electricity. PV panels, having no moving parts, are highly reliable, long lived, and require little maintenance. In addition, PV panels are highly modular. It is easy to assemble PV panels into an array that can meet any given sized load. The main disadvantage of PV is its high capital cost. Despite this, especially for small systems, PV is often a cost-effective option, with or without another power source, as the savings of use pays back the initial cost within a few years.

\section{PV Panel Construction}

PV panels consist of individual cells that are wired together in series and in parallel to produce the desired voltage and current. The cells are usually encapsulated in a transparent protective material and typically housed in an aluminum frame. As mentioned earlier, PV panels are long lasting with warranties that run as long as 20 years.

\section{Performance Characterization}

PV panels are rated in terms of peak watts $(\mathrm{Wp})$ or peak kilo-watts $(\mathrm{kWp})$. This rating is a function of both panel size and panel efficiency. This rating scheme also makes it easy to compare panels and prices from different suppliers. Panels should be compared in terms of cost per Wp. This rating is the amount of power that the panel will produce under standard reference conditions $\left(1 \mathrm{~kW} / \mathrm{m}^{2} ; 20^{\circ} \mathrm{C}\left[68^{\circ} \mathrm{F}\right]\right.$ panel temperature.) This is roughly the intensity of sunlight at noon on a clear summer day. Thus a panel rated at $50 \mathrm{Wp}$ will produce $50 \mathrm{~W}$ when the insolation on the panel is $1 \mathrm{~kW} / \mathrm{m}^{2}$. Because power output is roughly proportional to insolation, this same panel could be expected to produce $25 \mathrm{~W}$ when the insolation is $500 \mathrm{~W} / \mathrm{m}^{2}$.

Panel energy production can be estimated by multiplying the panel's rated power by the site's insolation on the panel's surface (typically $1400-2500 \mathrm{kWh} / \mathrm{m}^{2}$ per year; $4-7 \mathrm{kWh} / \mathrm{m}^{2} /$ day). The resulting product is then derated by approximately $10 \%-20 \%$ to account for losses caused by such things as temperature effects (panels produce less energy at higher temperatures) and wire losses.

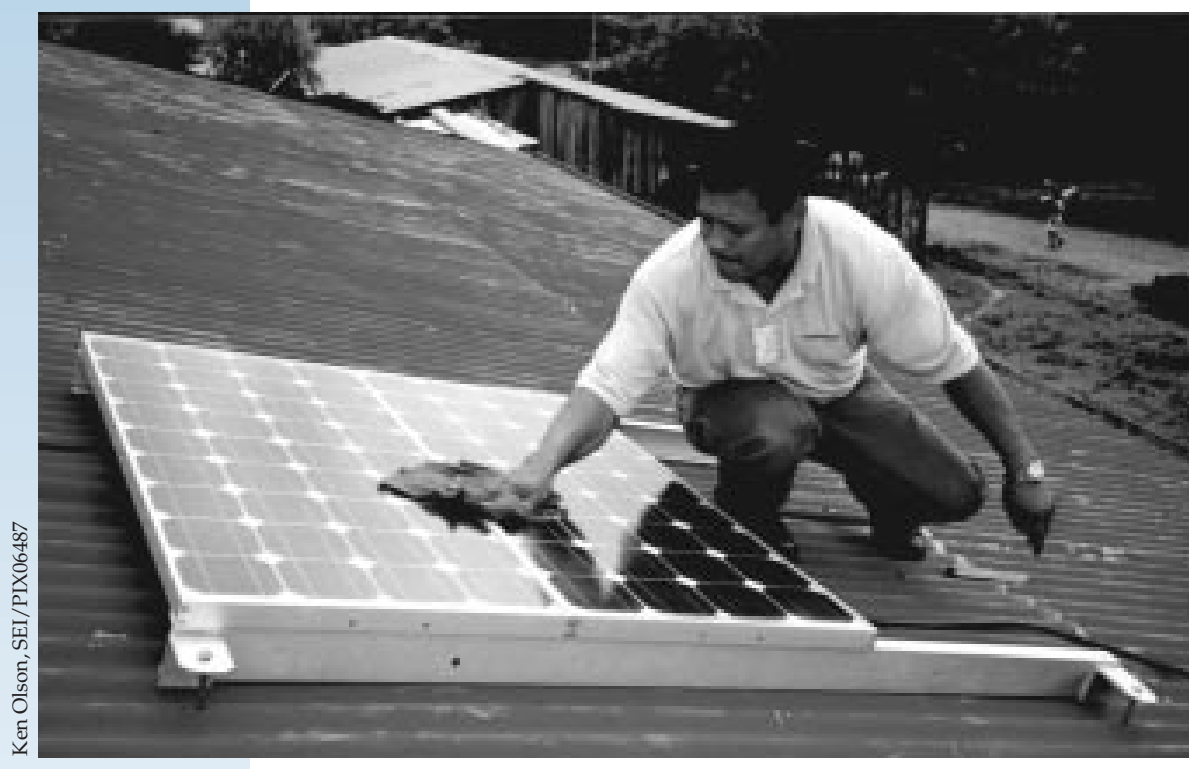

Figure 2.2. A photovoltaic technician cleans two 80-watt panels which power a Sunfrost vaccine refrigerator in the community of Mulukuku, Nicaragua.

\section{Panel Operation}

Most PV panels are designed to charge $12 \mathrm{~V}$ battery banks. Larger off-grid systems may have DC bus voltages of 24 , 48,120 or $240 \mathrm{~V}$. Connecting the appropriate number of $\mathrm{PV}$ panels in series enables them to charge batteries at these voltages. For non-battery charging applications, such as when the panel is directly connected to a water pump, a maximum point power tracker (MPPT) may be necessary. A MPPT will match the electrical characteristics of the load to those of the panel so that the panel can efficiently power the load. 


\section{Panel Mounting and Tilt Angles}

In order to maximize energy production, $\mathrm{PV}$ panels need to be mounted so as to be oriented towards the sun. To do this, the panels are mounted on either fixed or tracking mounts. Because of their low cost and simplicity, fixed mounts are most commonly used. These type of mounts can be made of wood or metal, and can be purchased or fabricated almost anywhere.

Tracking mounts (either single or dual axis) increase the energy production of the panels, particularly at low latitudes, but at the price of additional cost and complexity. The relative cost effectiveness of tracking mounts versus additional panels will vary from project to project.

\section{Capital and Operating Costs}

PV panels are available in a wide variety of ratings up to $100 \mathrm{Wp}$ and panels rated as high as $300 \mathrm{Wp}$ are manufactured. Individual PV panels can be connected to form arrays of any size. Panels may be connected in series to increase the array voltage, and can be connected in parallel to increase the array current. This modularity makes it easy to start out with a small array and add additional panels later.

The costs of a PV array are driven by the cost of the panels. Despite declining prices in the last two decades, PV panels remain expensive. Retail prices for panels bottom out at about $\$ 5,500$ per $\mathrm{kWp}$. For bulk purchases, prices can go below $\$ 4,000$ per $\mathrm{kWp}$. Warrantees typically are for 10 to 20 years. Current panels can be expected to last in excess of 20 years. The remaining PV array costs consist of mounts, wiring, and installation. These are typically $\$ 1,000-\$ 1,500$ per $\mathrm{kWp}$.

PV panels (not necessarily the remainder of the system) are almost maintenance free. Mostly, they just need to be kept clean, and the electrical connections need periodic inspection for loose connections and corrosion.

\section{Wind Turbine Generators}

\section{Introduction}

Wind turbines convert the energy of moving air into useful mechanical or electrical energy. Wind turbines need somewhat more maintenance than a PV array but with moderate winds, $>4.5$ meters per second $(\mathrm{m} / \mathrm{s})$, will often produce more energy than a similarly priced array of PV panels. Like PV panels, multiple wind turbines can be used together to produce more energy. Wind turbine energy production tends to be highly variable; therefore wind turbines are often best combined with PV panels or a generator to ensure energy production during times of low wind speeds. This section will focus on small wind turbines with ratings of $10 \mathrm{~kW}$ or less.

\section{Wind Turbine Components}

The components common to most wind turbines are shown in the diagram below. The blades capture the energy from the wind. The shaft connects the blades and the generator. In small wind turbines, the shaft usually drives the generator directly. Most small wind turbines use

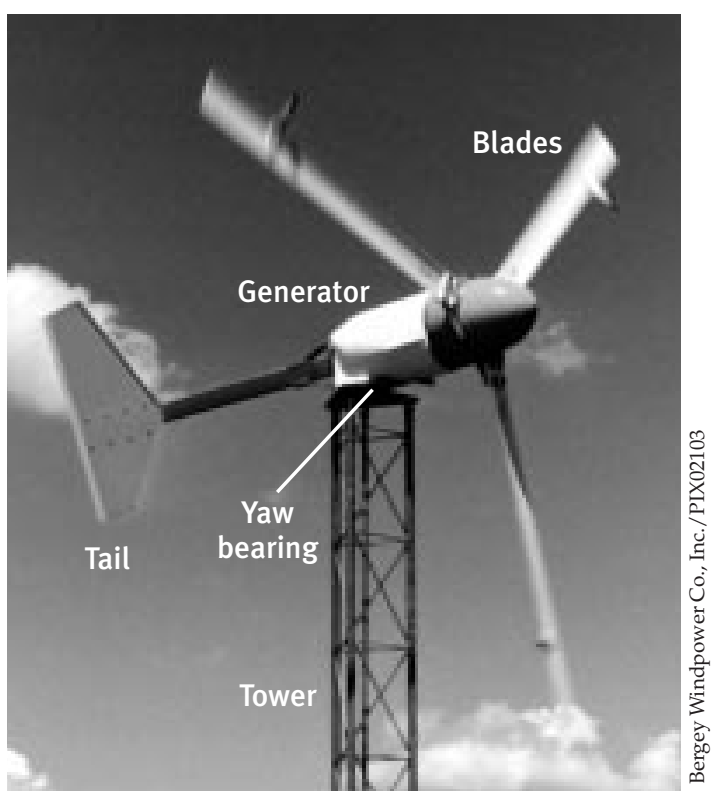

Figure 2.3. Typical wind turbine components 


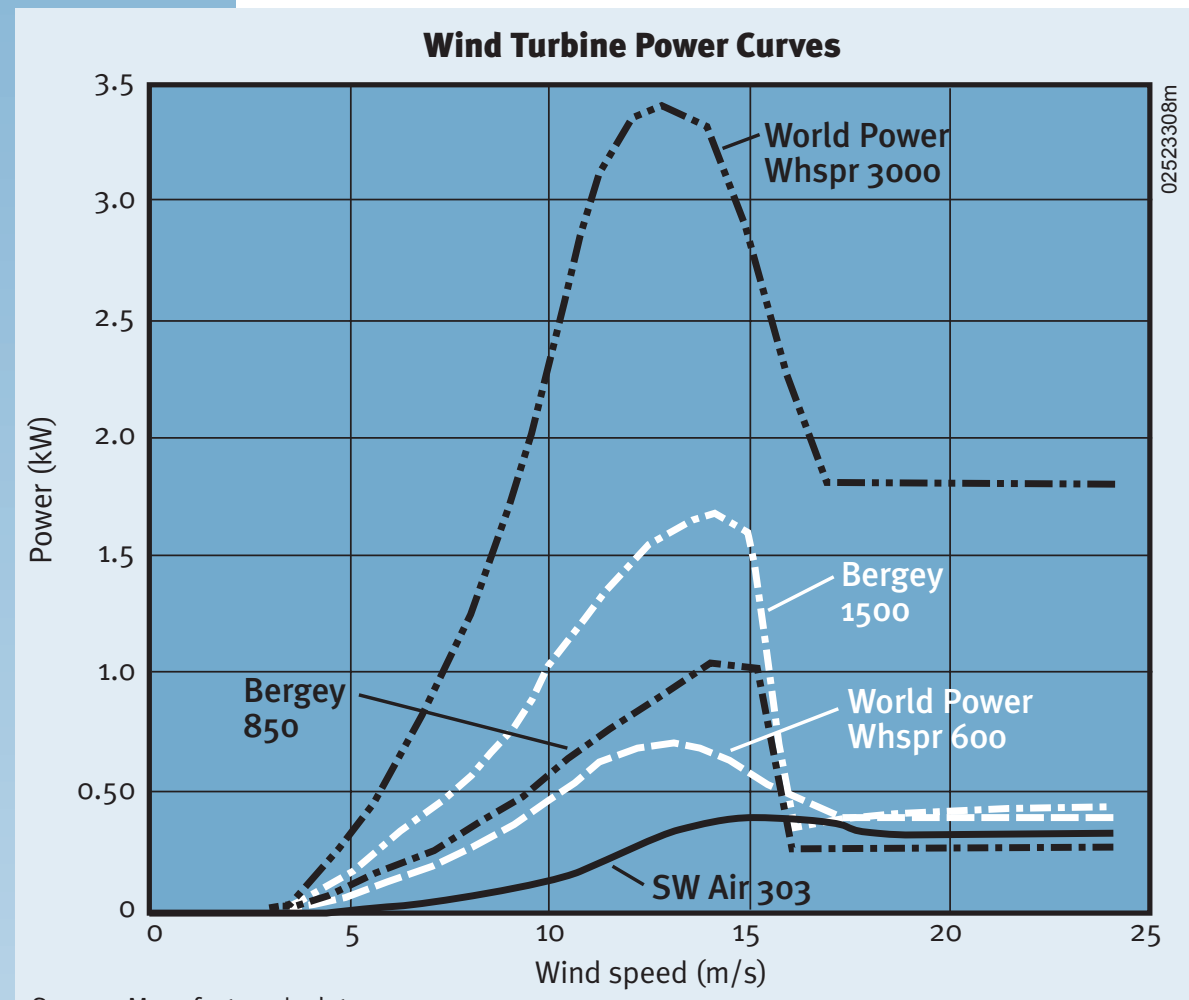

Source: Manufacturer's data rapidly with increasing wind speed until it starts leveling off as it approaches peak power. The energy density in moving air is proportional to the cube of the velocity. Thus, until the cut-out speed is reached, wind turbines produce much more power at higher wind speeds than at lower wind speeds. Most small turbines produce peak power at about $12-15 \mathrm{~m} / \mathrm{s}$. The turbine will produce at peak power until the wind speed reaches the turbine's "cut-out" speed. Cut-out speeds usually range from 14 to $18 \mathrm{~m} / \mathrm{s}$. Cut-out occurs to protect the turbine from over spinning in high winds. Most small turbines cut-out by passively tilting (furling) the nacelle and rotor out of the wind. After cutout, wind turbine power output usually does not decrease to zero, but remains at $30 \%-70 \%$ of rated power.

Wind turbines are rated by their power output at a specified wind speed, e.g., $10 \mathrm{~kW}$ at $12 \mathrm{~m} / \mathrm{s}$. Usually this rating is at or near the wind turbine's peak power output. The wind speed at which a turbine is rated is chosen arbitrarily by the manufacturer.

The non-linear nature of the wind turbine power curve makes long-term energy performance prediction more difficult than for a PV system. For long-term performance prediction , one needs the wind speed distribution rather than just the average wind speed. Long-term performance can then be calculated by integrating the wind turbine power curve over the wind speed distribution. Wind turbine performance may also depend upon the application for which it is used. the cut-in speed typically ranges from 3 to $4 \mathrm{~m} / \mathrm{s}$. After cut-in, wind turbine power increases 


\section{Wind Turbine Costs}

Wind turbine prices vary more than PV panel prices. Similar sized turbines can differ significantly in price. This is caused by wide pricing variations among different turbine manufacturers and to widely varying tower costs based on design and height. Installed costs generally vary from $\$ 2,000$ to $\$ 6,000$ per rated $\mathrm{kW}$. Unlike the case for PV, wind turbines offer economies of scale, with larger wind turbines costing less per $\mathrm{kW}$ than smaller wind turbines.

Maintenance costs for wind turbines are variable. Most small wind turbines require some preventive maintenance, mostly in the form of periodic inspections. Most maintenance costs will probably be due to unscheduled repairs (e.g., lightning strikes and corrosion). Gipe6, claims a consensus figure of $2 \%$ of the total system cost annually.

\section{Diesel Generators}

\section{Introduction}

Generators consist of an engine driving an electric generator. Generators run on a variety of fuels, including diesel, gasoline, propane and bio-fuel. Generators have the advantage of providing power on demand without the need for batteries. Compared to wind turbines and PV panels, generators have low capital costs but high operating costs.

\section{Cost and Performance}

Diesel generators are the most common type. They are available in sizes ranging from under $2.5 \mathrm{~kW}$ to over 1 megawatt (MW). Compared to gasoline generators, diesel generators are more expensive, longer lived, cheaper to maintain, and consume less fuel. Typical costs for small diesel generators (up to $10 \mathrm{~kW}$ ) are $\$ 800$ to $\$ 1,000$ per $\mathrm{kW}$. Larger diesels show greater economies of scale, costing roughly $\$ 7,000-\$ 9,000$ plus $\sim \$ 150$ per $\mathrm{kW}$. Typical diesel lifetimes are on the order of 25,000 operating hours. ${ }^{7}$ Overall maintenance costs can be estimated to be $100 \%$ to $150 \%$ of the capital cost over this 25,000-hour lifetime. Maintenance includes operator maintenance and periodic overhauls. Larger diesels are usually overhauled rather than replaced. Diesel generator fuel efficiency is generally $2.5-3.0 \mathrm{kWh} /$ liter when run at a high loading. Efficiency drops off sharply at low loads. It is this poor low-load efficiency that is the bane of many generator-only systems. The generator must be sized to cover the peak load, but then often runs at low load much of the time.

Less common than diesels, gasoline generators cost less and are available in very small sizes (as low as a few hundred watts). Otherwise, gasoline generators are inferior in most respects to their diesel counterparts. For sizes larger than about $1 \mathrm{~kW}$, prices range from $\$ 400$ to $\$ 600$ per $\mathrm{kW}$. The minimum price is roughly $\$ 400$ regardless of size. Lifetimes are short, typically only 1,000 to 2,000 operating hours. Fuel efficiency is

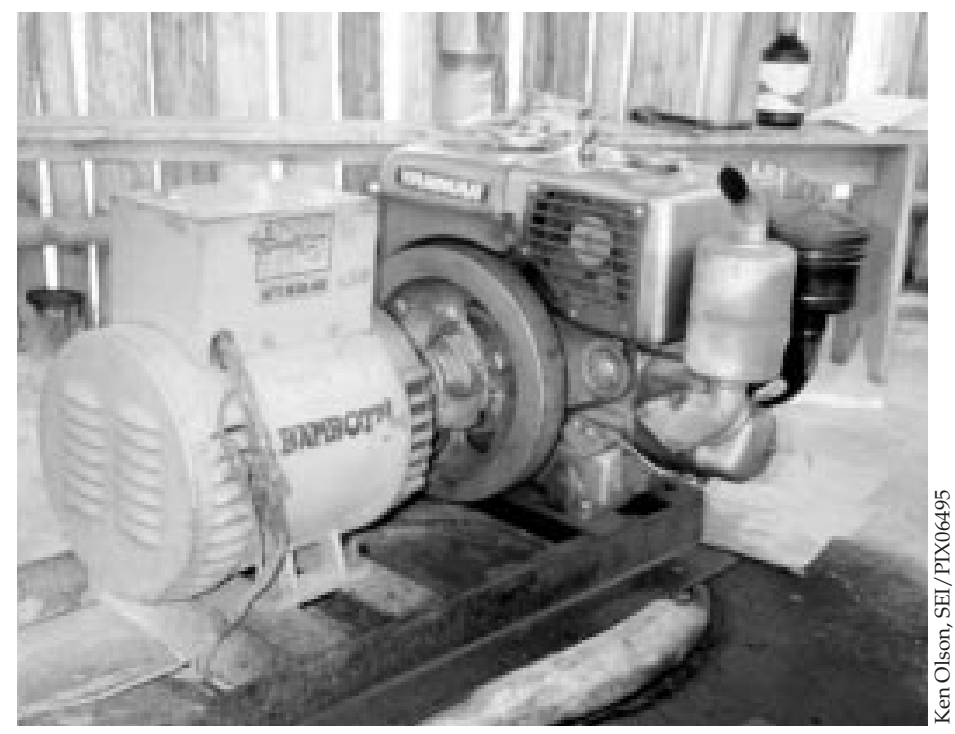

Figure 2.5. A diesel generator is the typical source of power at small rural hospitals. Smaller clinics may rely upon smaller gasoline powered generators for emergency use only. 
poor, peaking at roughly $2.0 \mathrm{kWh} /$ liter. Partload fuel efficiency is worse than for diesel generators. Gasoline generators are best used when the loads are very small or the anticipated run hours total no more than roughly 400-600 hours per year.

Given the previous discussion, several points regarding the optimum use of generators emerge. For maximum fuel economy, the generator should be run at a high load (>60\%). Conversely, low-load operation should be avoided. Not only does this decrease the fuel efficiency, but there is evidence that low-load operation results in greater maintenance costs.

\section{Batteries}

\section{Introduction}

Batteries are electrochemical devices that store energy in chemical form. They are used to store excess energy for later use. By far the most common type of battery is the lead-acid type. A distant second are the nickel-cadmium types. The remainder of this section discusses the leadacid battery.

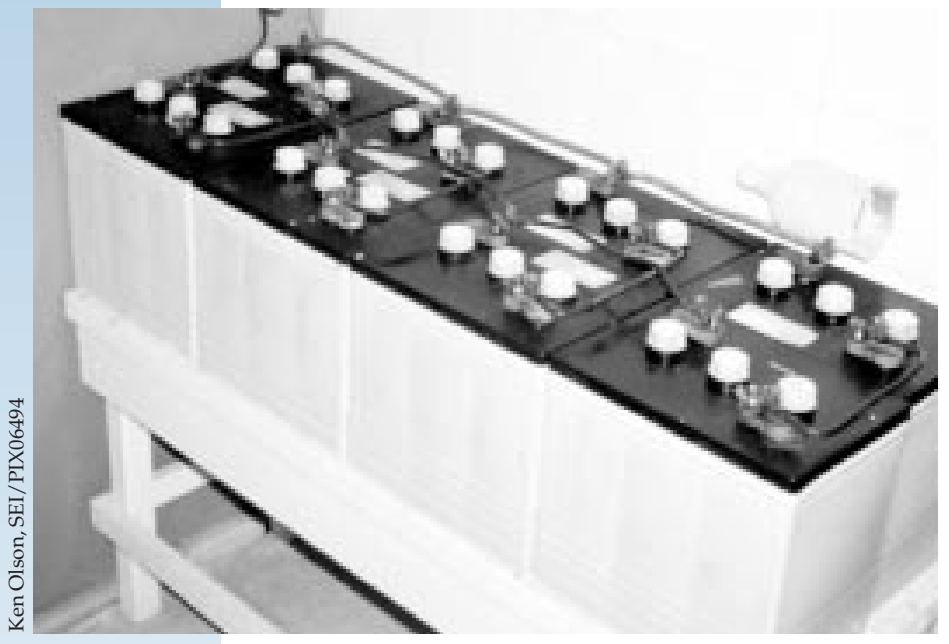

Figure 2.6. A bank of deep-cycle, lead-acid batteries provide energy to operate a vaccine refrigerator 24 hours per day. Photovoltaic panels or a wind generator can recharge the batteries.

\section{Battery Selection Considerations}

\section{Deep-Cycle versus Shallow-Cycle}

While batteries are sized according to how much energy they can store, in most cases a leadacid battery cannot be discharged all the way to a zero state of charge without suffering damage in the process. For remote power applications, deep-cycle batteries are generally recommended. They are designed to be discharged down to a $20 \%-50 \%$ state of charge. Shallow-cycle batteries, such as car batteries, are generally not recommended, though they are often used in small PV systems because of the lack of any alternatives. They can be prudently discharged only to an $80 \%-90 \%$ state of charge and will often be destroyed by only a handful of deeper discharges.

\section{Flooded versus Valve Regulated}

Flooded batteries have their plates immersed in a liquid electrolyte and need periodic rewatering. In contrast, in valve regulated batteries the electrolyte is in the form of a paste or contained within a glass mat. Valve regulated batteries do not need rewatering. Flooded batteries generally have lower capital costs than valve regulated batteries, can withstand more extreme operating conditions, and with proper maintenance, tend to last longer. On the other hand, where maintenance is difficult, valve regulated batteries may be the better choice.

\section{Lifetime}

Battery lifetime is measured both in terms of cumulative energy flow through the battery (full cycles) and by float life. A battery is dead when it reaches either limit. A full cycle is the equivalent of one full discharge and recharge. For example, discharging a battery twice to $50 \%$ is one cycle. For many batteries, as long as the battery state of charge is kept within the manufacturer's recommended limits, the number of cycles is roughly independent of how the battery is cycled. Depending upon the brand and model, battery lifetimes vary widely, ranging from less than 100 full cycles to more than 1500 full cycles. Float life refers to how long a battery that is connected to a system will last, even if it is never or only lightly 
used. Typical float lives for good quality leadacid batteries range between 3 and 8 years at $20^{\circ} \mathrm{C}\left(68^{\circ} \mathrm{F}\right)$. Note that high ambient temperatures will severely shorten a battery's float life. A rule of thumb is that every $10^{\circ} \mathrm{C}\left(18^{\circ} \mathrm{F}\right)$ increase in average ambient temperature will halve the battery float life.

\section{Costs}

The storage capacity of a battery is commonly given in amp hours at a given rate of discharge. When multiplied by the battery's nominal voltage (usually 2,6 , or $12 \mathrm{~V}$ ), this gives the storage capacity of the battery in $\mathrm{kWh}$. This storage capacity is not a fixed quantity, but rather varies somewhat depending on the rate at which the battery is discharged. A battery will provide more energy if it is discharged slowly than if it is discharged rapidly. In order to facilitate uniform comparison, most battery manufacturers give the storage for a given discharge time, usually 20 or 100 hours.

Individual batteries used in RE and hybrid systems are available in capacities ranging from 50 amp hours at $12 \mathrm{~V}$ to thousands of amp hours at $2 \mathrm{~V}(0.5 \mathrm{kWh}$ to several $\mathrm{kWh})$.

The variations in cycle and float life, described earlier, make comparison of the costeffectiveness of different batteries somewhat problematical. As a general starting point, costs are on the order of $\$ 70-\$ 100$ per $\mathrm{kWh}$ of storage for batteries with lifetimes of 250 to 500 cycles and float lives in the range of 3 to 8 years. There will be additional one-time costs for a shed, racks, and connection wiring.

\section{Inverters}

\section{Introduction}

Inverters convert DC to AC power. This capability is needed because PV panels, batteries, and most small wind turbines produce DC power. Most common electrical applications and devices require $\mathrm{AC}$ power.

\section{Types of Inverters}

Inverters fall into one of three classes, square wave, modified sine wave, and sine wave.

Square wave inverters are the least expensive but their output, a square wave, is suitable only for resistive loads such as resistance heaters. Modified sine wave inverters produce a staircase square wave that more closely approximates a sine wave. This type of inverter is the most common. Most AC electronic devices and motors will run on modified sine wave AC. Some sensitive electronics, such as computers and stereo equipment, may not work with modified sine wave $\mathrm{AC}$ and require sine wave inverters. These inverters can produce power that is indistinguishable from what comes out of the outlet, but they cost more than the other types of inverters.

For off-grid applications the inverter must have stand-alone capability, i.e., the inverter does not need to be grid connected in order to regulate voltage and frequency. High conversion efficiency, especially at part load, is desirable. If the system includes a generator, paralleling capability allows the inverter to operate simultaneously with the generator.

\section{Inverter Costs}

Inverters are usually sized according to their maximum continuous power output. Most inverters however, are capable of handling significantly more power than their rated size for short periods of time. This surge capability is useful for meeting the occasional oversized load such as starting a motor.

Inverter costs are roughly $\$ 600-\$ 1,000$ per $\mathrm{kW}$ for good quality modified sine wave inverters. The technology for inverters larger than $5 \mathrm{~kW}$ is not as mature as for smaller inverters and costs may be somewhat higher. 


\section{Controllers/Meters/Balance of Systems}

\section{Introduction}

Controllers and meters act as the brains and nervous system of an RE or hybrid system. Controllers route the energy through the system components to the load. Metering allows the user to assess system health and performance. In many cases, the various controlling and metering functions of a system will be spread out over several different components. The complexity of the controls depends upon the size and complexity of the system and the preferences of the user. Controllers have had problems with reliability and lightning, making careful controller design and lightning protection important considerations.

\section{Purposes and Functions}

- Battery high/low voltage disconnect: A highvoltage disconnect protects the battery against overcharging. A low-voltage disconnect protects the battery against over discharging. These are critical functions that should be included in all systems with batteries.

- Battery charging: A controller with a proper battery charge algorithm will do much to increase battery lifetime.
- AC and DC bus current and voltage monitoring: Monitoring the current and voltage on the DC and AC buses lets the user check that the components and system are properly operating.

- Turn components on or off: The controller can be programmed to turn components on and off as needed without user intervention.

- Divert energy to a dump load: The purpose of a dump load is to shed excess energy. Dump loads may be needed if the system contains wind turbines, micro-hydro, or generators. A dump load is essentially one or more big resistors that dissipate electricity by converting it to heat. Available dump loads are either water- or aircooled. Dump loads are sometimes used to control the frequency of the AC output of a system.

- Balance of system: The BOS includes the additional items such as wiring, conduit, and fuses that are needed to complete a system.

- DC source center use: Several manufacturers now offer DC source centers. These combine much of the system wiring, fusing, and controllers into one tidy, easier to install package. The use of source centers will increase system costs somewhat, but offer easier system installation, less complex wiring, and easier system monitoring and control. The use of a source center should be considered, especially for systems in remote sites that lack easy access to technical assistance. 


\section{CHAPTER 3: SYSTEM SELECTION AND ECONOMICS}

\section{Introduction}

The first section of this chapter describes lifecycle cost analysis and explains how and why it should be used when analyzing the economics of various options. The second part of this chapter discusses the various factors influencing system design, load, available resource, component costs, and desired level of service per these options. Included are charts that show how typical system costs vary as a function of load and resource.

\section{Life-Cycle Cost Analysis}

\section{Why Use Life-Cycle Cost Analysis?}

A common error when performing simple economic analysis is basing the analysis upon initial cost and short time periods. Because the total cost of a project is the sum total of its initial cost and its future costs, life-cycle cost (LCC) analysis is more appropriate. Initial costs are incurred at the beginning of the project; these typically include expenditures for equipment purchase and installation. Future costs are incurred later in the life of the project, including operation and maintenance costs such as personnel, fuel, and replacement equipment.

System options will have different combinations of initial and future costs, making consistent comparison between the options more difficult. This issue is particularly pertinent to health clinic electrification. RE options tend to have high initial costs and low operating costs. Generators have low initial costs but high operating costs. Choosing options based solely on initial cost may lead to higher overall costs over the life of the system.

LCC is the preferred method for evaluating the economics of different projects with differing initial and future costs. LCC involves calculating the total cost of an option by summing the discounted annual costs of that project over its lifetime. Any economics textbook will provide more details on how to do an LCC analysis. The results of LCC and most other economic analyses are sensitive to the inputs; thus parametric analysis should be done over a plausible range of input values.

LCC implicitly assumes that the options being compared provide comparable levels of service. If the options provide differing levels of service, this difference should be accounted for in the option selection process.

\section{Operating Costs}

Some RE projects fail or incur higher than expected operating costs caused by improper installation and lack of operator training. Sufficient project funds should be allocated to ensure proper training of installers and operators.

The cost of servicing single systems in dispersed communities can also contribute to high operating costs. The cost of servicing RE systems can be greatly reduced if the systems can be serviced locally and the service costs are shared with other applications in the community.

\section{Fuel Subsidies}

In many countries, fuel costs are artificially low because of government subsidies. To fully capture the potential operating cost savings offered by RE, economic analyses of any project where the government would pay for fuel should use the unsubsidized fuel cost. While economic analysis of private systems should use the subsidized fuel cost, the probability and effects of the removal of fuel subsidies some time during the lifetime of the project should be considered.

\section{Income Generation}

RE systems often produce excess energy, which can be used to generate income in the community. For example, a pilot project in Columbia, South America, has demonstrated 
that communities can use renewable energy systems to generate income to offset the operating costs of the health clinics. Refer to Case Study \#4 in Chapter 5. This income can be accounted for in the LCC analysis.

\section{Design Considerations and Economics}

This section describes the factors that affect system configuration and costs. The main considerations driving system selection are load, resource, costs (component, fuel, and operating), and quality of service.

\section{Load}

The load is a major driver of hybrid system design. A designer needs to know the peak load, the average load, the seasonal and diurnal load distribution and the quality of service needed. The system components, especially the wiring and power electronics, must be sized so that the system can deliver the peak load. The average load will drive the size of the energy producing components and will also influence the components selected. PV systems are most competitive at meeting very small loads such of the smaller health clinics described in this Guide. Wind turbines and generators become more competitive with somewhat larger loads found at the larger clinics. Diurnal and seasonal load variations must be considered and may influence component selection. Summer and daytime loads favor PV. Winter loads are more suited for generators and, if winter is the windy season, wind turbines are a good choice. If the wind and solar resource are seasonally complementary (i.e., the wind resource is good during the low-insolation season) then a wind-PV hybrid system may be more appropriate.

The last important load-related consideration is the quality of service desired. Quality of service refers to the system's capability to meet the load given the variabilities in the solar and wind resources. For a 100\% RE system, the costs may be excessive if very high quality of service is needed. If system components, especially the battery bank, are sized for the worst possible case, the system will be oversized at all other times.

An example of a critical load that needs reliable power is a vaccine refrigerator. A day or less without power is enough to ruin a batch of vaccines. Other loads are less critical. Lights, TVs, and water pumps are loads that can be used less during periods of reduced energy availability. Even vaccine refrigerators are amenable to limited load management. Refraining from freezing ice packs will significantly reduce the energy consumption of a vaccine refrigerator. Often a health clinic will have a mixture of critical and less critical loads. In this case, with proper load management, the system can be designed to be somewhat less robust than would be needed if all the loads were critical. During times of low resources, the less critical loads are turned off.

Even with the extra costs associated with high levels of service, $100 \%$ RE systems are often still the most cost-effective solution for meeting the small load demands of health posts and health clinics. A lower quality of service requirement will improve the economics of RE in general and wind turbines in particular.

\section{Resources}

The available wind and solar resources greatly influence both the configuration and the cost of a hybrid system. A good wind resource will favor the use of wind turbines, while a good solar resource will favor the use of PV. Another consideration is the variability of the resource, both daily and seasonally. The time period of importance may depend on the system configuration. For a stand-alone RE system, the designer might be more interested in the monthly average resource and size the PV array or wind turbines (or both) based upon the lowest resource month. For a system with generator backup, sizing the $\mathrm{RE}$ components using average annual resources may be more appropriate.

Most locations experience seasonal variations in solar insolation and wind speed distribution. These variations make it difficult to get 

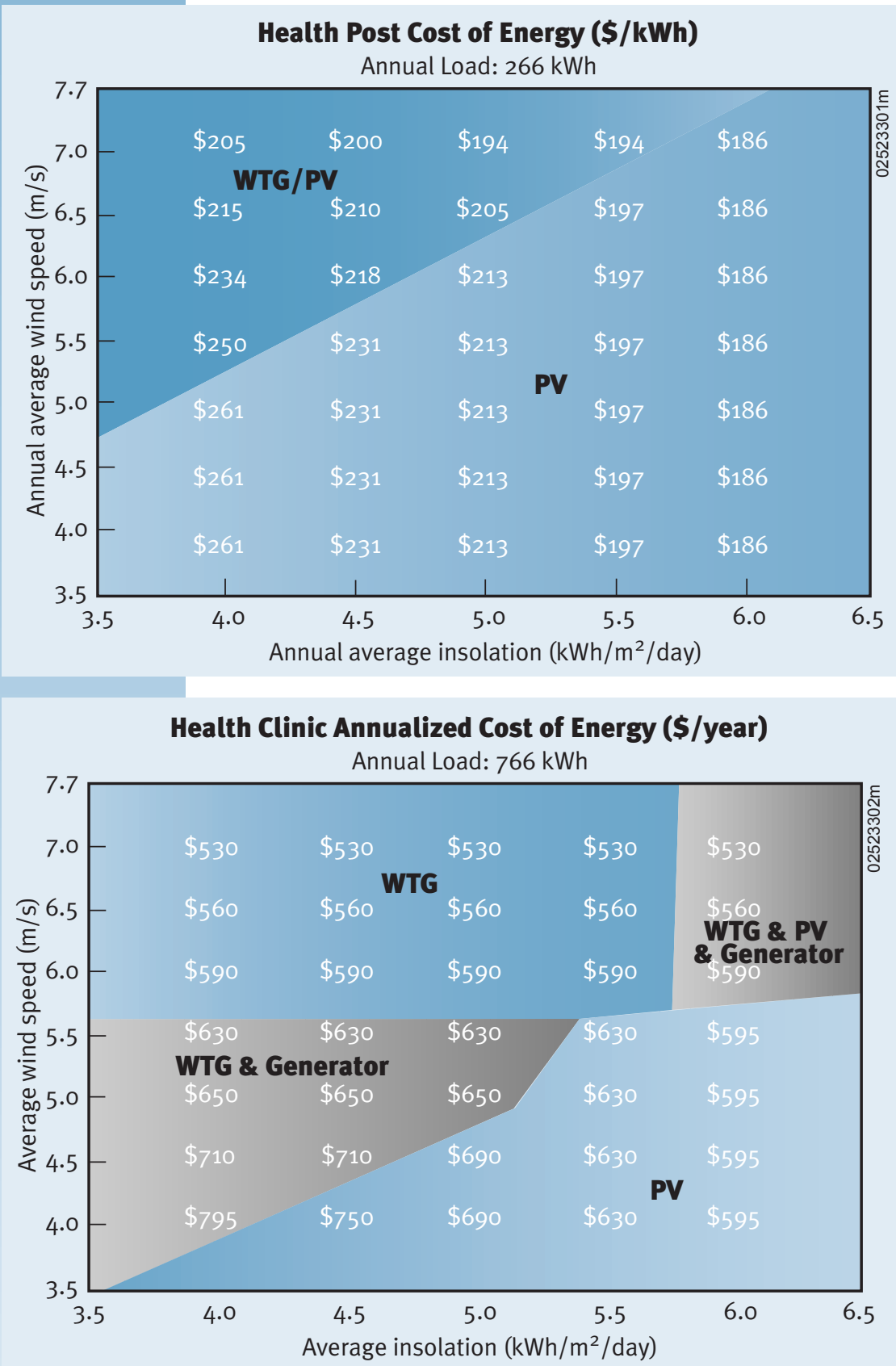

Figure 3.1. These graphs show the least-cost configurations for two differentsized health facilities as a function of average wind speed and average daily solar insolation. The costs given are the annualized cost (\$/year) of the lowest cost system with the given solar and wind resources. The results assume a particular set of economic assumptions. The same set of wind speed and insolation data was used for all runs and scaled to get the various annual average values shown. The results are meant to show general trends only. PV = photovoltaics, WTG = wind turbine generator. consistent production from PV arrays and wind turbines. Seasonal variations in insolation are usually driven by the changing length of the day as the seasons progress. This type of variation can be partially overcome by proper tilting of the PV panels. Insolation may also vary because of the existence of a rainy or cloudy season. The wind resource is also often seasonally variable. Even areas with relatively good winds often have a one or two month period of low average wind speeds. In this case a wind/PV, wind/diesel or wind/PV/diesel hybrid may be appropriate.

While long-term averages drive the sizing of the wind turbine and PV capacity, the short-term (on the order of days) fluctuations in wind and sun will influence the amount of storage required. The longer the expected length of lulls in the wind and sun, the larger the amount of storage needed. It is these lulls that drive up the cost of 100\% RE systems. Systems with generator backup do not need batteries sized to meet the largest anticipated lull in the resource.

Some of these points are illustrated in Figure 3.1. This figure shows, for a particular location and set of cost assumptions, how the configuration of the lowest cost system varies depending upon the local solar and wind resource. Figure 3.1 (top) shows the annualized system cost for a health post with an average load of 700 Wh per day. Figure 3.1 (bottom) shows the costs for a larger facility with an average load of $2 \mathrm{kWh}$ per day.

Figure 3.2. shows the typical range of costs for PV and wind turbine generator (WTG) systems over 

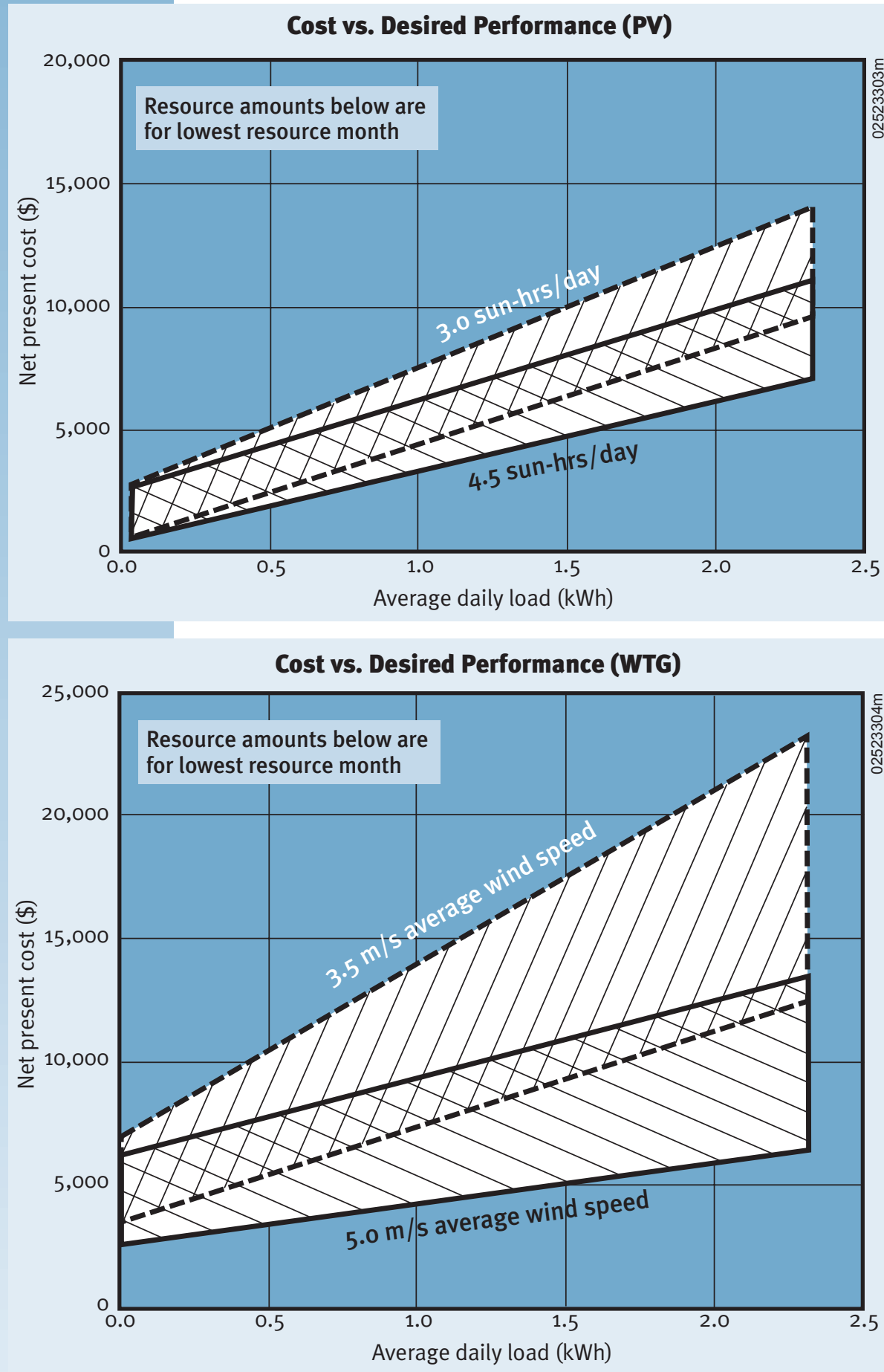

Figure 3.2. These graphs show the typical cost range of the listed technology (photovoltaic or wind turbines) for a system as a function of the average daily load. The resource availability listed (for both wind and sun) is the month with the lowest resource availability. a range of loads. Each graph shows two bands that reflect costs given two levels of resource availability. Because these are $100 \%$ RE systems the resource level is not the annual average, but rather the average for the worst month. A couple of examples will clarify the use of the graphs. Figure 3.2 (top) shows that a PV system capable of handling an average daily load of $0.5 \mathrm{kWh}$, in a locale with the worst month insolation (3.0 sun hours/day), is expected to have a 25 year net present cost of between $\$ 2,500$ and $\$ 5,000$. Figure 3.2 (bottom) shows a WTG system that meets an average daily load of $1.0 \mathrm{kWh}$ costs between $\$ 4,000$ and $\$ 8,000$ in a location with a worst month average wind speed of $5.0 \mathrm{~m} / \mathrm{s}$.

\section{Generator Considerations}

For larger loads (above $\sim 1 \mathrm{kWh}$ /day), a big decision is whether or not to use a generator. Ultimately, this decision will depend upon an analysis of the site in question. The big advantages of generators are their ability to provide power on demand. The disadvantage of generators is high operating costs because of fuel and maintenance. Providing fuel and maintenance to remote sites is often problematical. Figure 3.3. shows the 25-year net present cost (NPC) of a $2.5 \mathrm{kWh}$ diesel generator as a function of average daily load and average daily run time. The figure plainly shows that it is the 


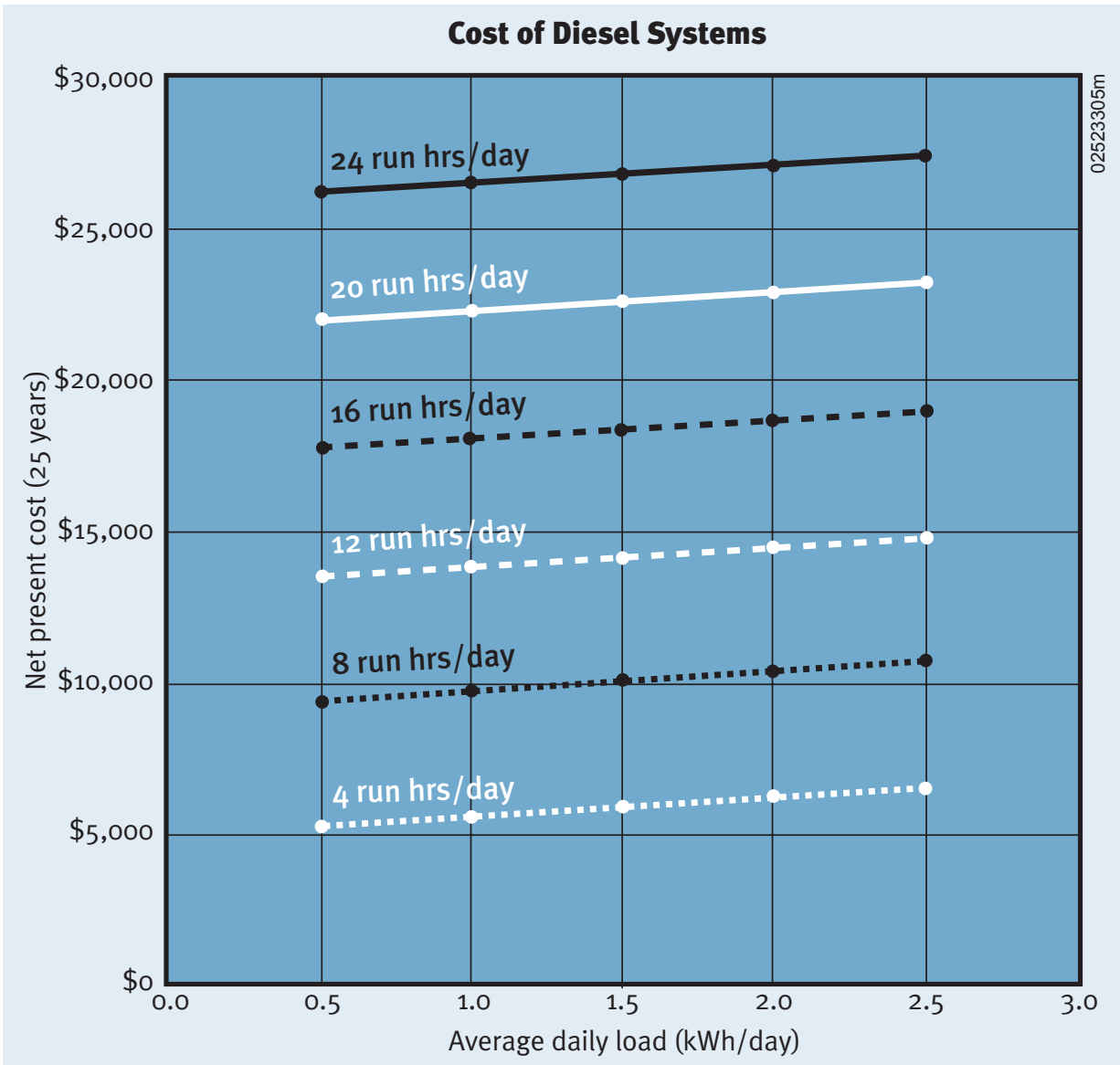

Figure 3.3. This graph shows the 25 year net present cost of using a diesel generator. The two variables are average daily load (kWh/day) and daily run hours. Note that the costs only vary slightly with load but escalate rapidly with increasing run hours.

number of operating hours that drives the cost of using a generator. If the number of operating hours is low, generators can be competitive sources of energy. As the operating hours increase, costs escalate. If the loads consist of things such as lights and water pumps that are only on a few hours per day, then an all-diesel system may be cost competitive.

If the generator must be run more than a few hours per day, another solution is needed. One possible solution is to use a generator-battery system. When the generator runs it charges a battery bank that then is used most of the time. The savings from reduced generator run time vastly outweigh the conversion losses caused by cycling energy through the battery.

The other solution is to combine the generator with PV panels, wind turbines, or both. The $\mathrm{RE}$ components minimize the generator run time, keeping the generator operating costs to a minimum. The generator precludes the need to oversize the RE components and thus reduces the capital costs. 


\section{CHAPTER 4:} INSTITUTIONAL CONSIDERATIONS

\section{Chapter Introduction}

While focusing mostly on various institutional, organizational, and social issues that should be addressed prior to initiating a largescale project, much of the information in this chapter is also applicable to smaller scale projects as well. The last part of this chapter discusses the advantages and disadvantages of various types of public sector and private sector combinations when implementing a health clinic electrification plan.

The overall issues of cost and reliability are foremost in the minds of those responsible for health services. Technology is no longer the barrier to realizing the benefits of RE technologies. How technologies are integrated institutionally is another frontier. Institutional aspects of policy, planning, management, financing, service infrastructure, community participation, and user interface are critical to the successful use of any chosen technology.

\section{General Considerations}

\section{Policy and Commitment}

A national policy framework is key to the integration of RE into health clinic electrification. Without an established policy at the highest level and commitment at every other level, efforts to implement RE technologies run a high risk of failure. Many health professionals responsible for allocation of limited financial and human resources for public health programs see RE technologies as costly, experimental technologies with a history of failures. They may be unaware

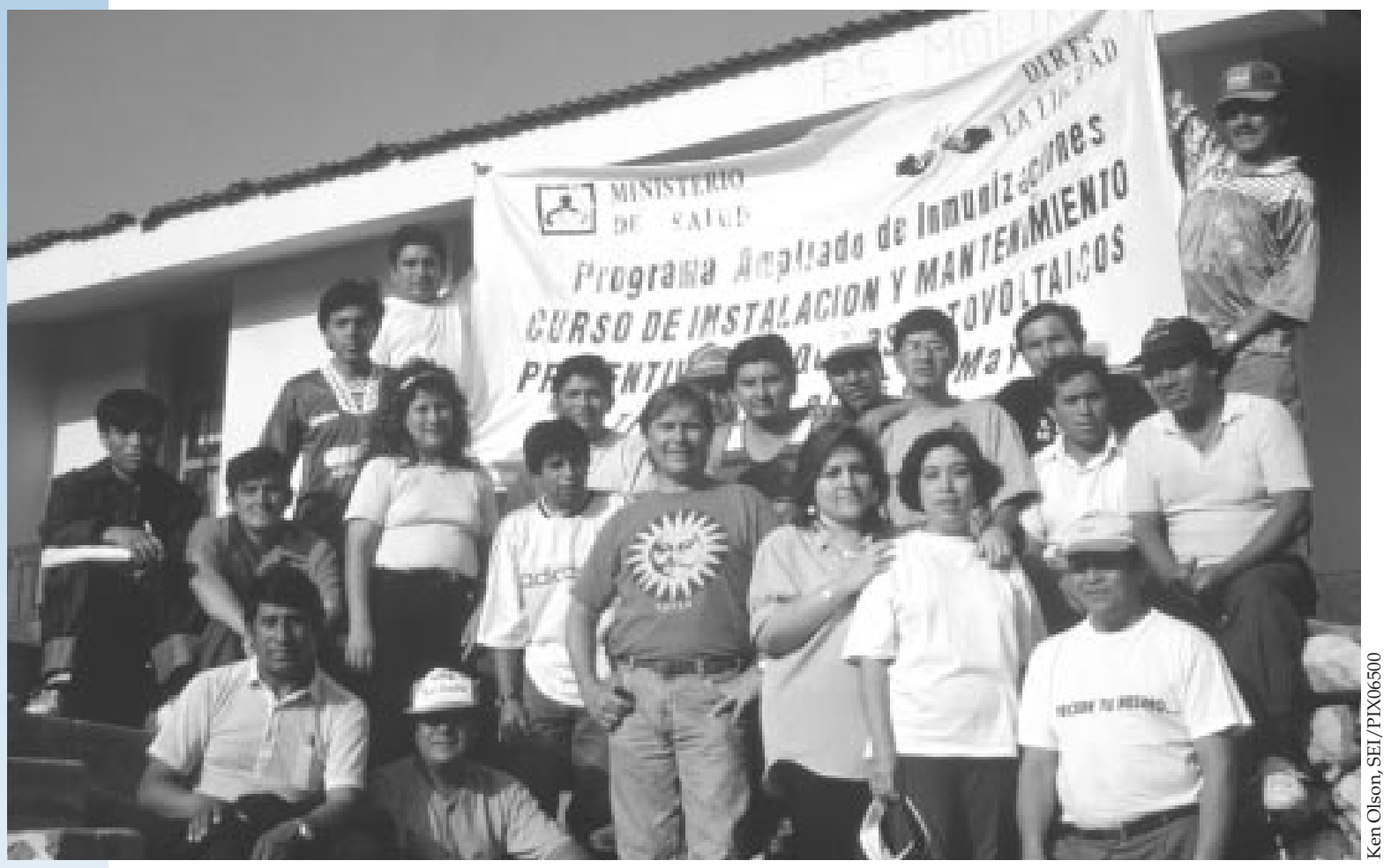

Figure 4.1. Regular technician training courses, such as this one in Peru, build local skills and knowledge. A qualified and able service infrastructure is essential to support renewable energy systems in the field. 


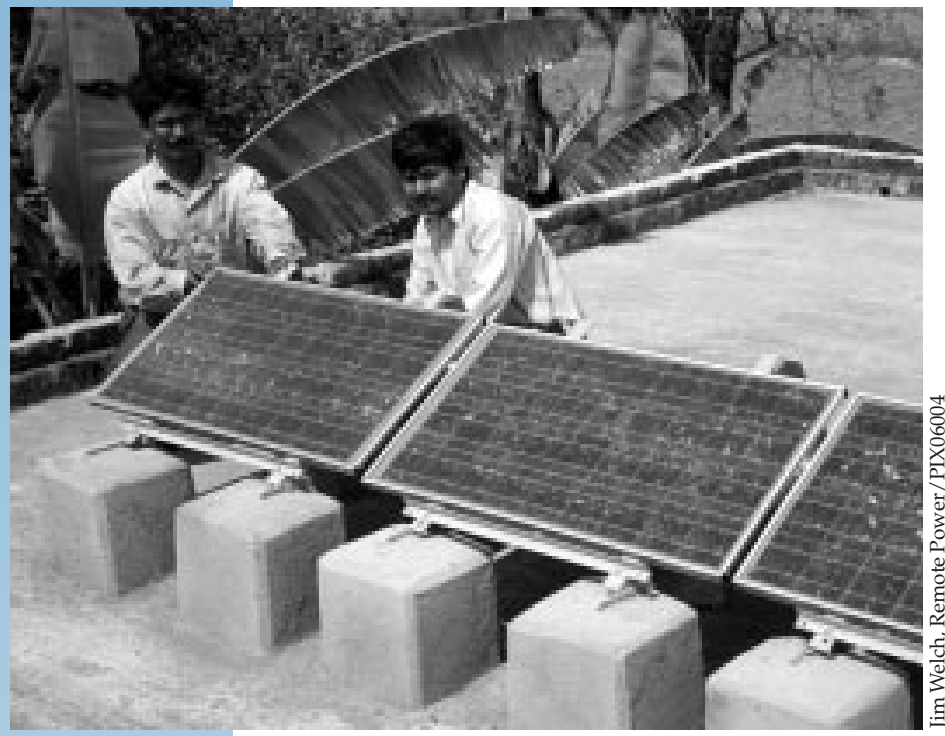

Figure 4.2. Technicians install photovoltaic modules on a village clinic in West Bengal, India.

of the benefits of successful applications. Promotion of RE development should be accompanied by the removal of barriers such as import duties and subsidies for fossil fuel power.

Partnerships offer the ability to share resources, costs and benefits. Collaboration with other community sectors such as education and agriculture is beneficial to the mission of public health programs. Similar needs such as light for education and safe community water supply can share the same service and share its costs. Collaboration between public and private entities should seek to support public health with private commercial services.

\section{Decision-Making and Management}

In some instances RE systems failed to prove reliable. These experiences have often left the perception that RE is more costly and requires special skills and knowledge. Without quality standards and proper service these failures will be repeated. The selection and procurement of quality systems and service must be based upon standards of acceptance and quality control. Adequate resources for logistics, servicing, and maintenance must be allocated.
Higher quality service is the strongest argument for integrating RE into health care. Cost analysis is usually based upon the initial cost. LCC analysis can be a favorable argument for renewable energy choices but is not a determinant.

\section{Service Infrastructure}

Although the technologies are mature, there lacks a well-developed, reliable service industry to install, maintain, and repair systems in the field. This infrastructure can be developed more cost effectively through partnerships with other human service sectors to share costs.

System designers and field technicians must receive regular training and information to retain current knowledge and skills. There must be enough pay for their services to keep them available and prepared. Spare parts must be available. The system users must be aware of the proper operation and care for the system. Training must be adequate and regular.

\section{Financing and Income Generation}

Availability of financing for purchase of equipment will put the benefits of RE technologies within the reach of those that need them most. National governments and international donors have provided significant capital funds for clinic electrification with marginal results. The lack of operating funds for maintenance and repair soon renders the equipment unusable.

There are numerous examples of revolving credit funds to support productive use enterprises and enable individuals to purchase solar lighting systems as a means of rural electrification. The principles of these successes should be applied to community-based health facilities and enterprises. Strategies to generate income at the local level can enable recovery of the loan funds and provide operating funds to maintain the equipment.

\section{Community and Culture}

Dynamics within the community play an important role in making or breaking the success 
of a project. The community and its individuals may support, ignore, abandon, or even subvert the system. Systems and services provided must be in the appropriate language and level of education to be understood.

\section{Institutional Configurations}

A variety of institutional configurations may be considered for integration of renewable energies into public health care. Whatever configuration is most appropriate for a given country, factors to be accounted for include:

- Policy

- Project management

- Financing

- Training and technical assistance

- Systems design

- Systems installation

- Maintenance and repair

- Quality control.

Configurations that have been used include a variety of public and private arrangements. There are advantages and disadvantages to each.

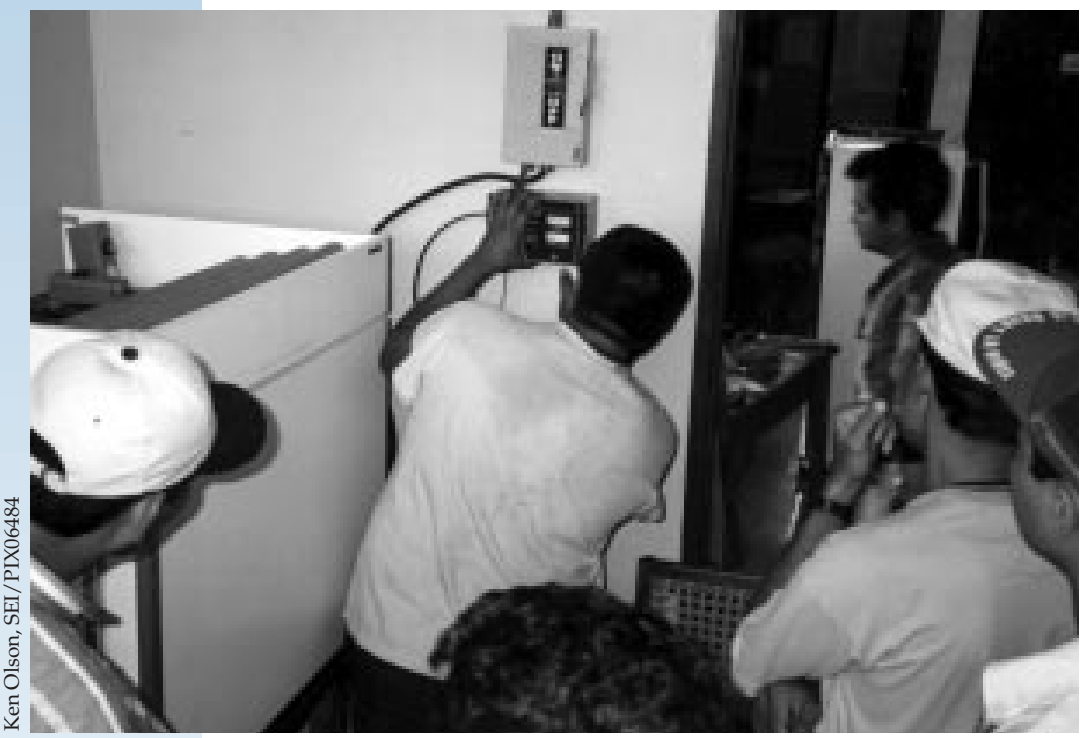

Figure 4.3. A photovoltaic technician's course completes the final installation checklist prior to commissioning a photovoltaic powered refrigerator/freezer at Clinica in the community of Mulukuku, Nicaragua.

\section{Management and Implementation by Government}

In this institutional configuration, the government ministry of health carries out all aspects of the planning, system design, installation, maintenance, and repair of RE systems.

\section{Advantages:}

- National health programs have an established infrastructure of planning, management, technical, and logistical support to rural health centers. This existing infrastructure may be adapted to support RE systems.

- Programs on a national scale may be large enough to have sufficient critical mass to develop and support a service infrastructure.

\section{Disadvantages:}

- Government bureaucracies are often inefficient in providing services. Bureaucratic processes are usually slow, particularly when involving purchases and travel expenses for installation, maintenance and repair.

- Technical staffs are often insufficient in numbers to accommodate the needs of all regions of the country.

- Ministry of health technicians, may be familiar with the health care systems, but will need training in the installation, maintenance, and repair of RE systems. They often lack the proper tools and resources.

\section{Management by Government and Implementation by Private Contractor}

In this institutional configuration, the government ministry plans the program to utilize RE, and issues requests for bids to provide equipment and services. Private contractors provide equipment along with installation services. The contractor may provide maintenance and repair services under a service agreement. Alternatively, the ministry of health 
may accept those responsibilities once the installation is complete and accepted.

\section{Advantages:}

- Private contractors in the business of selling and installing renewable energy systems are usually equipped with the knowledge, skills, and tools to provide the required services as needed on a contractual basis.

- A ministry of health may be better prepared to establish the scope of work and manage implementation than to actually perform the work with its own personnel.

\section{Disadvantages:}

- If no clear specifications exist for procurement of equipment, bidders propose systems with varying specifications. This makes it difficult to evaluate and select from proposals with unequal attributes.

- Many bureaucratic purchasing processes automatically select the lowest bidder without regard for significant differences in the relative quality of proposals submitted.

- There is often a lack of Standards of Acceptance for quality of installation in the field. Deficient installations have a high rate of failure, pose a threat to reliability to health care services, and result in higher costs for maintenance and repair.

- Private contractors are not always competent to install systems professionally in the field. They often are in need of technical training.

- Private contractors are unfamiliar with the specific needs of health care systems.

- Training of the system users is often forgotten or incomplete.

\section{Management and Implementation by Non-Governmental Organizations}

Many non-governmental organizations (NGOs) provide health care services in rural communities. In this configuration, the NGO procures, owns, operates, maintains, and repairs the system on its own.

\section{Advantages:}

- NGOs are often run by committed and motivated individuals who operate efficiently and effectively on limited budgets. Decision-making and project implementation is generally less bureaucratic than a government process.

- NGOs generally have strong community relationships. As a result, they may be more readily able to generate community support and participation as well as collaborate with other service sectors such as education, agriculture, and enterprise.

\section{Disadvantages:}

- NGOs generally operate programs for a limited number of establishments which they operate and maintain themselves. This scale of program does not lend itself to significant support of a commercial service infrastructure.

- NGOs typically do not have the specialized technical knowledge or skills to implement RE technologies without technical assistance.

- Small NGOs often have cash flow problems. 


\section{CHAPTER 5: CASE STUDIES}

\section{Chapter Introduction}

This chapter presents five case studies, three of which are the result of one of the author's (Ken Olson) visits and direct observations. Each case study highlights different aspects of health clinic electrification. Combined, the case studies provide valuable lessons that can be used to improve future health clinic electrification projects.

\section{CASE STUDY \#1- Photovoltaics for Immunization: Experience in Africa}

Sources: World Health Organization. (1996). "Solar Energy and Rural Health Care." WHO Fact Sheet N132. Geneva, Switzerland. Available at http:/www.who.int/inf-fs/en/fact132.html.

World Health Organization. Report of 1991 Technet Consultation, Casablanca, Morocco. Order no. WHO/EPI/LHIS/92.1. Geneva, Switzerland.

\section{The Cold Chain Program}

The Cold Chain is a system of people and equipment present in almost all countries, which attempts to keep vaccines at proper temperatures as they are distributed from the manufacturer to the locations where they are administered. Fail-safe refrigeration within a specified range of temperature, from point-ofmanufacture to point-of-use is critical to the mission of the Cold Chain.

Absorption refrigeration fueled by propane or kerosene has been the most common method for preserving vaccines at unelectrified health clinics. It has also been the weakest link in the Cold Chain in terms of reliability. PV powered compression refrigerators are now replacing absorption units for greater reliability and better temperature control.
Experiences with PV powered vaccine refrigerator/freezers in Africa were evaluated by WHO and reported in November 1991 Technet Consultation. The conclusions and lessons learned then are still meaningful today. The recommendations arising from that evaluation have shaped policy and programs for the increased use of solar energy in rural health care.

The early experiences with PV powered units showed much higher reliability as compared to gas units. The mean time between failures for PV vaccine refrigerators was 2.6 years in Uganda and 4 years in the Gambia, both much lower than could have been achieved with better basic maintenance by the health staff.

The failure rate of kerosene refrigerators was much higher. In Mali, kerosene refrigerators exceeded the $8^{\circ} \mathrm{C}\left(46^{\circ} \mathrm{F}\right)$ degree maximum temperature an average of $20 \%$ of the time. Temperatures were often as high as $25^{\circ} \mathrm{C}\left(77^{\circ} \mathrm{F}\right)$.

Temperature control of the kerosene units is very poor in climates with high diurnal temperature ranges, and particularly in climates with daytime temperatures of $35^{\circ} \mathrm{C}\left(95^{\circ} \mathrm{F}\right)$.

The economic evaluation showed the longterm cost of the gas units to be less than that of PV units. The higher cost of the PV units was primarily caused by the need to bring skilled technicians to remote areas for installation, maintenance, and repair. There were few technicians with a depth of experience in PV applications. WHO concluded that for remote health clinics with difficult access, the higher degree of reliability of PV units justifies their higher initial cost. In addition, WHO concluded that the operating costs of the compression units could be reduced with adequate training and cost sharing with other applications.

Since 1991, PV equipment costs have decreased and in-country training programs have increased local skills and knowledge, thereby lowering installation and service costs. A further reduction in these service costs can be achieved by sharing with other sectors such as rural electrification for commercial, agricultural, and residential applications. 
Typical Solar Vaccine Refrigerator Life Cycle Cost Breakdown Total Cost Range \$3500-\$4500 (US \$)

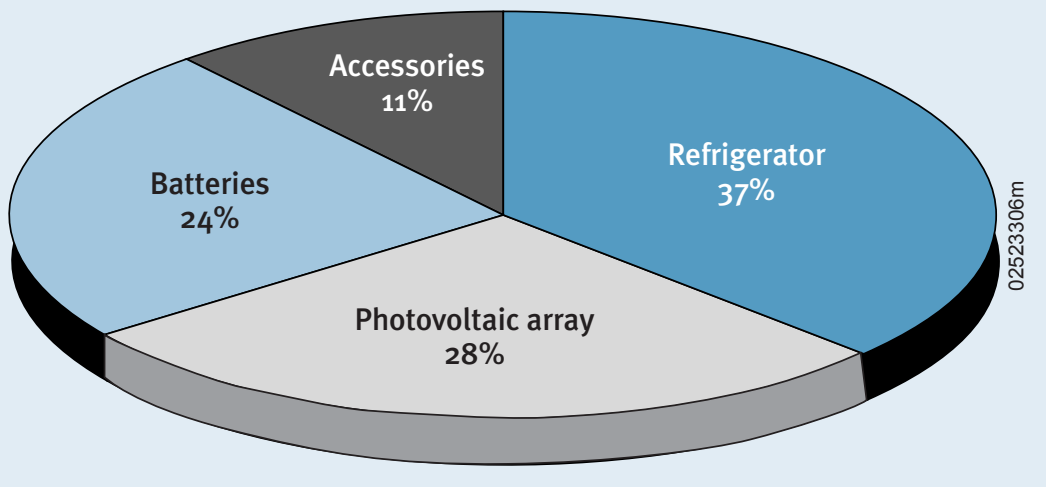

Subsequent to the 1991 evaluation, PV powered refrigeration was introduced more aggressively into the Cold Chain. As of 1993 all 54 health centers in the Gambia had replaced kerosene and gas units with PV units. Some centers were also provided with solar lighting and water heating. In Zaire and Uganda, $38 \%$ and $17 \%$, respectively, of the vaccine refrigerators were PV powered. In Kenya, only a small portion of the 1500 rural health clinics were using solar refrigerators until 1991when a severe gas shortage disrupted the fuel supply and shut down immunization services

Figure 5.1. Life-cycle cost breakdown of a photovoltaic powered vaccine refrigerator.

In summary, the evaluation of solar energy use in the Cold Chain in Africa concluded that $P V$ vaccine refrigeration improved the long-term reliability of the Cold Chain by increasing the mean time between failures. PV refrigerators also permitted a more strategic placement in remote areas and therefore are able to serve a wider area and greater population.

It was also concluded that there was a need for improved maintenance and services. The costs of service should be more widely shared with other solar energy applications outside of health services. Solar generated electricity has the potential to generate revenue through community video, water pumping, lighting and other community services.

Based upon the 1991 evaluation, WHO recommendations called for development of the following:

- Guidelines for countries wishing to consider PV powered refrigeration as an option

- Criteria for the development, implementation, and evaluation of other solar technologies for primary health care

- Specifications for PV powered refrigeration system components

- Improved manufacturer's guarantee. in seven districts of the country. Since then, Kenya has begun to expand it's use of PV powered vaccine refrigerators. In Zaire, a health clinic generated $36 \%$ of the costs of the immunization program in the district through a PV powered video theater and battery charging services.

Other countries have increased their use of PV powered vaccine refrigerators; the number of refrigerators in each country follows.

-Peru 300

-Indonesia 400

-Zambia 250

- Eritrea 200

-Myanmar 300.

\section{CASE STUDY \#2- Photovoltaic Powered Health Clinic: Chihuahua, Mexico}

Source: Ken Olson, personal observations November 1997

\section{Loads}

Compression-Type Vaccine Refrigerator

A thermostat that is set to $4^{\circ} \mathrm{C}\left(39^{\circ} \mathrm{F}\right)$ controls a $60-\mathrm{W}$ compressor. The actual energy consumption is determined by a number of variables such as ambient air temperature and usage. The system is designed in this case for an energy 
consumption of $0.44 \mathrm{kWh} /$ day which the unit will consume while maintaining a vaccine temperature within the range of $0^{\circ} \mathrm{C}-8^{\circ} \mathrm{C}\left(32^{\circ} \mathrm{F}-39^{\circ} \mathrm{F}\right)$ and freezing 2.2 kilograms of icepacks at an ambient air temperature in the health clinic of $32^{\circ} \mathrm{C}$ $\left(90^{\circ} \mathrm{F}\right)$. These are the conditions under which WHO tested the unit in order to approve it for vaccine conservation.

\section{Refrigerator Data}

Make/Model \#: Sunfrost RFVB Refrigerator/Freezer

Type: Compression type runs on 12 V DC electricity

Vaccine Storage

Capacity: 17.5 liters

Icepack Freezing

Capacity:

2.8 kilograms @ $0^{\circ} \mathrm{C}\left(32^{\circ} \mathrm{F}\right)$ ambient air temperature (@energy consumption below)

\section{Refrigerant: $134 \mathrm{amp}(\mathrm{A})$}

This refrigerator was tested by the Camara Ambiental testing facility in Cali, Colombia which tests vaccine refrigerators to determine if they meet WHO standards of performance. All units that meet WHO standards are described in Reference 8.

\section{Fluorescent Tube Lights}

Four 20-W lights are used an estimated 3 hours per day. These are standard tubes readily available in the area. The ballast is standard magnetic ballast. There are no reflectors or lenses equipped with the fixture. The 20-W consumption rated for the fixture does not include the energy consumption for the ballast, which is generally estimated at $2 \mathrm{~W}$. The average daily energy consumption at 3 hours of use per day per fixture is calculated at:

Two fixtures $\times 22 \mathrm{~W}$ each $\times 3 \mathrm{hrs} /$ day $=$ $132 \mathrm{Wh} /$ day $(0.132 \mathrm{kWh} /$ day $)$

Total average daily load $=0.572 \mathrm{kWh} /$ day

\section{PV System Specifications}

\section{PV Array}

$159 \mathrm{~W}$ (peak) will produce an estimated $0.588 \mathrm{kWh} /$ day in the month of least sun.

Three 53-W polycrystalline PV panels are mounted on a pole next to the health clinic where they are tilted at an angle equal to the latitude $\left(30^{\circ}\right.$ North) and unshaded from 8 A.M. until 4 P.M. year-round. Each panel will produce 3.08 A in full sun, or 9.24 A for all three together. The climate in Chihuahua receives the least amount of sun during the month of December when the panels will be exposed to the equivalent of 5.3 hours of full sun each average day. The panels will charge the $12-\mathrm{V}$ batteries with 49 A-hrs/day. The total load was estimated to be $0.572 \mathrm{kWh} /$ day.

In each of the other months of the year when there is more sun, the panels will produce more energy than required by the PV powered vaccine refrigerator and lights.

\section{Batteries}

Four deep-cycle, lead-acid batteries are each rated at $220 \mathrm{~A}-\mathrm{hrs} @ 6 \mathrm{~V}$. They are configured at 440 A-hrs @ 12 V. As this type of battery is designed to be discharged to no more than $80 \%$ of rated capacity, $352 \mathrm{~A}-\mathrm{hrs}$ are available for energy storage.

\section{Control}

A series-type PV controller protects the batteries from being over charged. The controller is rated at $20 \mathrm{~A}$, which is more than sufficient to handle the 9.24 A produced by the PV Array.

$$
\begin{aligned}
& \text { Table 5.2. Energy Consumption of a } \\
& \text { Sunfrost Vaccine Refrigerator } \\
& (\mathrm{kWh} / \text { day })^{8} \\
& \text { Refrigerator Freezer } \\
& \text { Ambient temperature } \quad 32^{\circ} \mathrm{C} \quad 43^{\circ} \mathrm{C} \\
& \text { Daily energy consumption ( } k W h \text { ) } \\
& \begin{array}{lll}
\text { With icepack freezing } & 0.44 & 0.59
\end{array} \\
& \begin{array}{lll}
\text { Without icepack freezing } \quad 0.30 & 0.38
\end{array}
\end{aligned}
$$




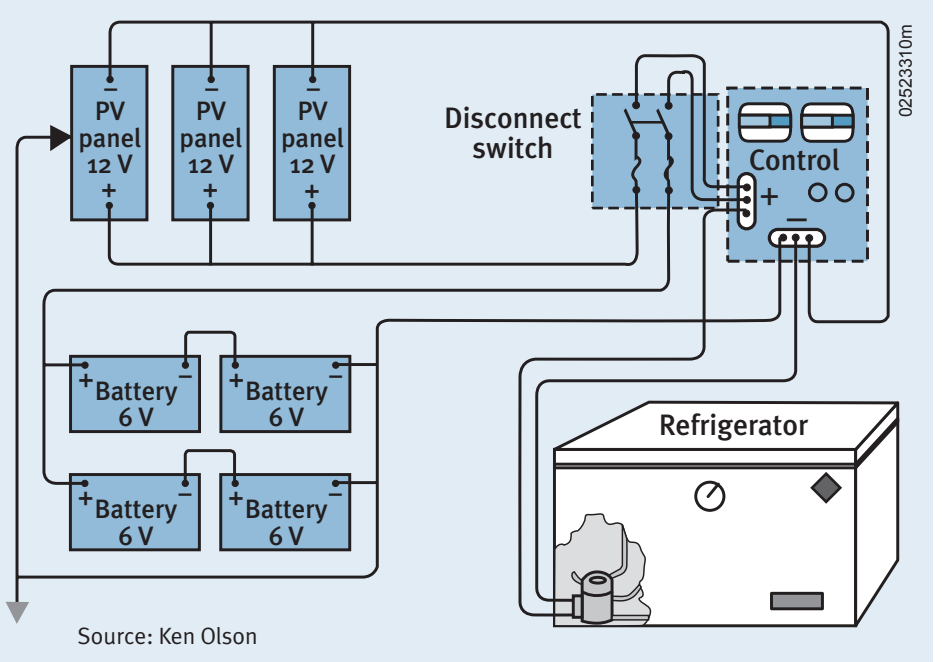

Figure 5.2. System block diagram

This leaves some room for additional panels in the future if desired.

\section{Experience to Date}

The system has maintained stable vaccine temperatures since the day it was installed. After two years, however, it was observed upon inspection that the batteries were in need of distilled water. The health clinic staff was unaware of the need to maintain the electrolyte level in the batteries with distilled water. Without the proper maintenance, this system would have failed causing the batteries to be replaced. With proper maintenance it is anticipated to operate reliably for 20 years or more with batteries being replaced every 5 years.

\section{CASE STUDY \#3- 300 Photovoltaic Powered Health Clinics: Peru's National Program}

Source: Ken Olson, personal observations, 1995-1996

\section{Introduction}

A national program to conserve vaccines by using photovoltaic refrigerators was established in Peru in 1995. A total of 300 PV powered vac- cine refrigerator/freezers have been installed to date.

The national program is administered at the national level by the Ministry of Health, with technical support from the Pan American Health Organization. The management of the program includes planning, procurement, training, implementation, and evaluation. These activities require coordination at the national, regional, and local levels.

Initially there was little to no experience with PV technologies in the health sector of Peru. There was a great need to improve immunization coverage, which required a higher quality of vaccine preservation, particularly at the local level. Trained technicians in each region understand compression refrigeration well, but had no experience with PV technology.

\section{Planning}

Planning for the placement of PV powered vaccine refrigerators was based upon the greatest need for improved reliability in immunization programs. Data is continuously collected and reviewed with respect to population demographics, incidents of cases of Polio, Measles, Tuberculosis, Diphtheria, and other diseases, as well as immunization coverage. Problem areas were identified with respect to weaknesses in the immunization program and cost of logistical support. This evaluation of needs in the health sector provided the basis for selecting sites for installation of PV powered vaccine refrigerators.

\section{Procurement}

System specifications based upon WHO recommendations were identified and provided the basis for three procurements consisting of 48 units in 1995, 118 units in 1996, and 50 units in 1997. Previous and subsequent procurements bring the total number of installed PV powered refrigerators in Peru to 300.

\section{Training Program}

A training program was carried out for 15 technicians familiar with the Cold Chain 
Program. The program consisted of classroom lab and field installations for the purpose of training technicians to install, maintain, trouble shoot, and repair PV powered vaccine refrigerator/ freezers. Management staff also participated to learn aspects of PV equipment and the logistics required for the program.

Technicians installed three systems during the course so that each would gain practical field experience in installation. Each technician also learned the logistical requirements of being prepared to successfully complete an installation at a remote location. They learned how to evaluate the solar insolation at each site and how to meet the standards of acceptance for a reliable installation. Technicians also learned to train the health staff in the proper operation and maintenance of the system.

Participants in the course were required to pass a series of quizzes and examinations as well as perform a required minimum skills demonstration test to successfully pass the course. Successful completion of the course qualified them to work with an experienced technician on field installations before being qualified to complete an installation on their own.

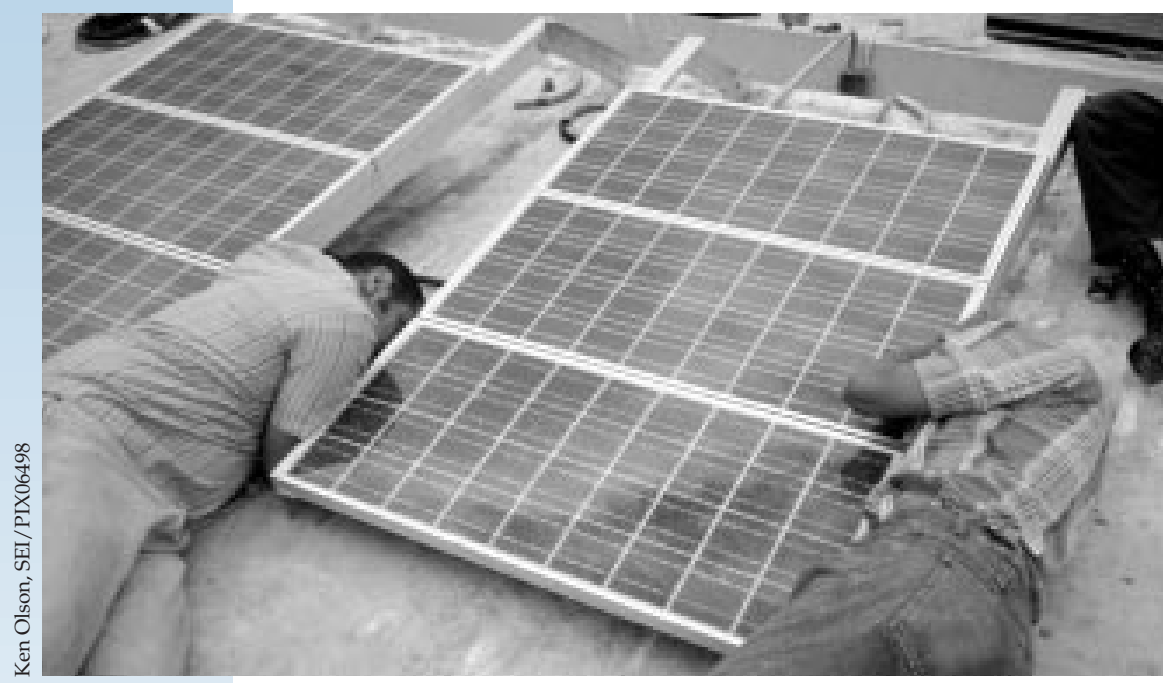

Figure 5.3. Technicians install photovoltaic panels on the roof of Clinica El Molino, near Trujillo, Peru.

\section{CASE STUDY \# 4- Photovoltaics for Health: An Integrated Approach}

Source: Dierolf, Carlos F., Celis Geovanny; "Energia Solar para la Salud" Un Enfoque Integrado: Segundo Informe de Progreso, Cubriendo el periodo Noviembre, 1995-Mayo, 1996; Remitido como requisito parcial de: acuerdo para el desarollo de trabajo Reg. File EPI/I9/181/1.95.10; Cali, Junio 15, 1996

Location: Chocó, Colombia, South America, 1995

Partners: World Health Organization/

PanAmerican Health Organization

Government of Holland

\section{Goals}

- Improve health services with use of photovoltaic technology.

- Make the photovoltaic systems sustainable with community participation.

- Demonstrate the feasibility of rural electrification at rural health facilities.

\section{Objectives}

- Generate community income to support health services

- Community-based microenterprises to generate income

- Income to support operations and maintenance

- Establish a community council

- Provide training

- Technical training to maintain solar energy systems

- Micro-enterprise training. 


\section{Summary}

Four rural remote communities in the Province of Chocó, on the Pacific Coast of Colombia utilize PV systems to provide health care services of vaccine refrigeration, lighting, communications, and medical appliances.

Each of four communities established community councils to create micro-enterprises to generate funds for maintenance of the PV systems. The community councils received PV systems to power micro-enterprises including four video theaters, two battery charging stations and the sale of PV powered lanterns. Four churches also received lighting systems. Two technicians were selected from each community and were trained in the installation, troubleshooting, maintenance, and repair of the systems.

\section{PV System Specifications (Docordo)}

1. Vaccine refrigerator/freezer

- Vaccine refrigerator/freezer

- Five 55-W PV Modules

- 200 A-hr lead-acid, deep-cycle batteries

- One PV control

2. Health clinic system loads

- Seven 20 W DC fluorescent lamps for emergency room, delivery room, laboratory, pediatric, nurses room, men's room, and women's room

- Short-wave radio

- Nebulizer (AC)

- DC receptacle

- Centrifuge (AC)

- Microscope lamp (AC)

- Five 55-W PV Modules

- Four 6-V, 150 A-hr batteries (300 A-hr @ 12 V)

- PV control (capacity 20 A@12 V)

- One 140-W inverter (12 V DC to 120 VAC)

3. Doctor's house

- Five 20-W fluorescent lamps
- One 53-W PV Module

- One 50 A-hr deep-cycle, lead-acid battery

- One Receptacle for $12 \mathrm{~V}$ television or radio

4. Video Theater

- One TV (19" color)

- One VCR

- Two 20-W fluorescent lamps

- Two 53-W PV modules

- Two 50-A-hr 12 V batteries (100 A-hr @ 12 V)

- One PV Controller

- One 300-W inverter

\section{Conclusions}

- Income generated by each of the four communities for operations and maintenance at the health clinics during the nine month period of April-December 1995 was as follows:

$\begin{array}{llll}\text { - Docordo } & \$ 420 & \text { - Guineal } & \$ 655 \\ \text { - Noanama } & \$ 335 & \text {-Orupa } & \$ 496 .\end{array}$

- The project was well accepted by each of the communities and health institutions. There was not however active participation from the local authorities.

- Rural Health Services were improved by the PV systems

- Vaccination coverage was increased

- Diagnosis of Malaria was more rapid

- Emergency communications were effective

- Lighting improved the quality of health clinic night visits

- Lighting improved the quality of staff residences

- Health education was improved

- Reduction in home accidents from kerosene lamps.

- Community participation was effective in generating funds to maintain PV systems for health care. 
- Community councils need assistance with

- Management skills

- Knowledge of market for PV

- Direct relation with suppliers

- Establishment of a financial credit program to expand the market for PV systems.

- The future of taking these successes on a large scale will depend upon innovative financing, investment and development of a private market for energy.

\section{CASE STUDY \#5- Dominican Republic}

Source: Ken Olson, personal observations 1994-1996

\section{Overview}

A national program to integrate PV technology into the health sector in the Dominican Republic offers significant lessons to be learned. The European Community donated US $\$ 1,000,000$ to the government of the Dominican Republic for the purpose of electrifying health clinics with PV powered vaccine refrigerator and lighting systems.

\section{System Specification}

Each health clinic was designed to receive the same system consisting of a vaccine refrigerator, and four lights. Each system was provided with six 50 W PV panels, four deep-cycle lead-acid batteries and a controller. Each system cost $\$ 6,000$.

\section{Planning and Implementation}

The initial plan was to carry out a pilot program of 20 systems and evaluate the experiences prior to completing the balance of the project. No evaluation was conducted at the conclusion of the pilot phase and a total of 164 systems were installed. After one year, it was observed that there was a high rate of failures in the installed systems. A subsequent evaluation revealed that after one year of service, $25 \%$ of the systems failed to function and $60 \%$ required repair, primarily replacement of batteries. Fifteen percent of the systems functioned without problems.

There were several mistakes made that could have been avoided if an evaluation of the pilot phase had been carried out.

- The refrigerator chosen was very inefficient. It was a domestic model retrofitted to operate on $12 \mathrm{~V}$. It was not an approved vaccine refrigerator and consumed more energy than the panels were capable of producing in most climates.

- Each system was design identically without regard for the solar insolation available in each climate.

- Installers of the system were inexperienced and untrained.

- Some systems had insufficient wire size resulting in excessive voltage drop in the system.

- Systems were located at health clinics that were neither unelectrified nor remote.

\section{Lessons Learned}

As a result of the evaluation it was recommended that

- Standards be developed for the placement, design, procurement, installation, and servicing of PV systems

- A training program be established to certify system designers, installers, and users

- Funds be allocated for regular maintenance

- A maintenance program must be established. 


\section{CHAPTER 6: \\ LESSONS LEARNED}

\section{Chapter Introduction}

Many lessons have been learned from past experiences. Lessons learned are a valuable resource for future success. These experiences apply at all levels: institutional, operational, system design, technology and development.

\section{Institutional}

- A policy framework to integrate RE resources into public health care must be supported with political will and commitment.

- Perceptions are often inaccurate or over simplified. Common misperceptions are that RE power systems are unaffordable, a future technology, or that they require no maintenance.

- Donor funded programs often fail for lack of operating funds and the local service infrastructure.

- Existing local service infrastructures may be adapted to provide routine maintenance and timely repair.

- Partnerships with credible community-based organizations are essential to success.

- Evaluation of cost based only upon initial cost discourages the choice for RE sources.

- Cost analysis often lacks consideration for non-comparable qualities of service.

- There are great potential benefits from cooperation with other human service sectors such as education, agriculture, safe water supply, economic development, and communications. These links are in need of development.

- Energy supply in the local community can generate income to support operating expenses.

- Energy supply in the local community has need for and the ability to economically support a commercial service infrastructure.

\section{Operational}

- Lack of maintenance is common and leads to system failure.

- Lack of installation standards of acceptance leads to system failure.

- Users are often unaware of the proper operation, care, or limitations of systems. Metering is often not understood or is confusing to the user.

- Training must be thorough and ongoing.

- Logistics are often underfunded and too bureaucratic.

- There is often a lack of spare parts, particularly with special parts.

- Systems should be supplied as complete as possible.

- Pilot projects must be replicable and utilize proven technologies.

- Pilot projects must be of a manageable scale for those implementing them.

- Pilot projects must be monitored and evaluated prior to implementation of full-scale projects.

\section{Systems Design}

- Lack of procurement standards leads to confusion on the part of suppliers and often results in the least cost, least robust option.

- Higher efficiency results in lower costs.

- Energy systems should be integrated with end use application.

- The energy system/application must be the least-cost, highest benefit option to meet the needs of public health care.

- Systems should be designed and provided as completely and detailed as possible.

- Adequate technical and user manuals must accompany systems and equipment.

- One size does not fit all. Systems must be properly designed for particular site conditions. 
- Sophisticated electronics may be vulnerable to damage by lightning.

\section{Technology and Development} Needs

- There is a need for more reliable resource data.

- The implementation process may require several (4-6) years for full start-up. Implementation is then on-going.

- Choices must be driven by programmatic needs rather than technology.

- Program planners need reliable and understandable information regarding energy choices. 


\section{REFERENCES}

1. World Health Organization. (1996). "Solar Energy and Rural Health Care." WHO Fact Sheet N132. Geneva, Switzerland. Available at http://www.who.int/inf-fs/en/fact132.html.

2. Werner, D.; Sanders, D.; et al. (1997). The Politics of Primary Health Care and Child Survival. HealthWrights, 946 Hamilton Ave., Palo Alto, CA, 94301.

3. World Health Organization. (1997). World Health Report 1997. Geneva, Switzerland. Available at http://www.who.int/whr/1997/ whr-e.htm.

4. World Health Organization. (1980). The Primary Health Care Worker, Rev. Ed. Geneva, Switzerland.

\section{World Health Report 1997.}

6. Gipe, P. (1993). Wind Power for Home and Business. Chelsea Green Publishing Company, White River Junction, Vermont.

7. Cowen, W.D.; Borchers, M.L.; Eberhard, A.A.; Morris, G.J.; and Purcell, C. de V. (1992). Remote Area Power Supply Design Manual. 2 vols, Energy for Development Research Center, University of Cape Town, Cape Town, South Africa.

8.World Health Organization. (1997). Product Information Sheets. Order no. WHO/EPI/ LHIS/97.01. Geneva, Switzerland. The Product Information Sheets have been produced by the Expanded Programme on Immunization in collaboration with the UNICEP Supply Division and two WHO Programmes: the Programme for Acute Respiratory Infections (ARI) and the Blood Safety Programme (BLS).

\section{BIBLIOGRAPHY}

Cabraal, A.; Cosgrove-Davies, M.; and Schaeffer, L. (1996). Best Practices for Photovoltaic Household Electrification Programs. World Bank Technical Paper \#324, Asia Technical Department Series, Washington, D.C.

Cardinal, J.; Flowers, L.; Taylor, R.; and Weingart, J. (1997). Proceedings of Village Power' 97.

NREL/CP-440-23409. National Renewable Energy Laboratory. Golden, Colorado.

Cowen, W.D.; Borchers, M.L.; Eberhard, A.A.; Morris, G.J.; and Purcell, C. de V. (1992). Remote Area Power Supply Design Manual. 2 vols, Energy for Development Research Center, University of Cape Town, Cape Town, South Africa.

Cross, B., ed., (1995). The World Directory of Renewable Energy Suppliers and Services 1995. James \& James Sciences Publishers, Ltd., London, United Kingdom.

Dierolf, C. F. and Celis G. (1996). “Energia Solar para la Salud: Un Enfoque Integrado": Segundo Informe de Progreso, Cubriendo el periodo Noviembre, 1995-Mayo, 1996; Remitido como requisito parcial de: acuerdo para el desarollo de trabajo Reg. File EPI/I9/181/1.95.10; Cali, Columbia, 15 Junio 1996.

Duffie, J. A., Beckman, W.A. (1991). Solar Engineering of Thermal Processes. 2nd ed., John Wiley \& Sons, Inc., New York.

Durand, J.M., Zaffran, M., "Sale of Excess Solar Energy: a Contribution to the Recurrent Costs of Immunization Programmes"

Fowler Solar Electric Inc. (1991). Battery Book for Your PV Home. Worthington, Massachusetts.

Gipe, P. (1993). Wind Power for Home and Business. Chelsea Green Publishing Company, White River Junction, Vermont.

Gregory, J.; Silveira, S.; Derrick, A.; Conley, P.; Allinson, C.; Paish, O. (1997). Financing Renewable Energy Projects: A Guide for Development Workers. Intermediate Technology Publications, London, and The Stockholm Environment Institute 1997. 157 pp. 
Hankins, M. (1993). Solar Electric Systems for Africa: A Guide for Planning and Installing Solar Electric Systems in Rural Africa. rev. ed.; Commonwealth Science Council \& AGROTEC; London, United Kingdom and Harare, Zimbabwe.

Hankins, M. (1993). Solar Rural Electrification in the Developing World, Four Country Case Studies: Dominican Republic, Kenya, Sri Lanka, Zimbabwe. Solar Electric Light Fund; Washington D.C.

Hunter, R. and Elliot, G., ed. (1994). Wind-Diesel Systems: A Guide to the Technology and it's Implementation. Cambridge University Press, Cambridge, United Kingdom.

Independent Development Trust. (1995). “Model Clinics Programme: IDT \& United States Department of Energy." Cape Town, South Africa.

$25 \mathrm{pp}$.

Independent Development Trust. "IDT Electrification of Clinics in the RSA." Cape Town, South Africa. 7 pp.

Jimenez, A. C. (1998). Optimal Design of StandAlone Power Systems for Remote Rural Health Facilities. Master's Thesis; Colorado State University; Fort Collins, Colorado.

McNelis, B.; Derrick, A.; and Starr, M. (1992). Solar Powered Electricity: A Survey of Photovoltaic Power in Developing Countries. Intermediate Technology Publications, London, United Kingdom.

Nelson, V. (1996). Wind Energy and Wind Turbines. Alternative Energy Institute, West Texas A\&M University, Canyon, Texas.

Pan American Health Organization. Twelfth Technical Group Meeting on Vaccine-Preventable Diseases: Conclusions and Recommendations, Guatemala City, Guatemala, 8-12 September 1997. Special Program for Vaccines and Immunization.

Sandia National Laboratories. (1995). Stand Alone Photovoltaic Systems: A Handbook of Recommended Design Practices. Report \# SAND87-7023, Sandia National Laboratories, Albuquerque, New Mexico.

Solar Energy International (1998). Photovoltaic Design Manual. 2nd ed., P.O Box 715, Carbondale, Colorado, 81623.
Werner, D.; Sanders, D.; et al. (1997). The Politics of Primary Health Care and Child Survival. Health Rights; Palo Alto, California.

World Health Organization. Conclusions and Recommendations on Solar Energy and Health for the World Solar Summit, Paris 1993. Order no. WHO/EPI/LHIS/93.4 Geneva, Switzerland.

World Health Organization. (1996). Integration of Health Care Delivery. WHO Technical Report Series \#861. Order no. 1100861. Geneva, Switzerland. $73 \mathrm{pp}$.

World Health Organization. (1994). Maintenance and Repair of Laboratory, Diagnostic, Imaging and Hospital Equipment. Order no. 1150423. Geneva, Switzerland. 164 pp.

World Health Organization. (1978). Primary Health Care: A Joint Report by the Director-General of the World Health Organization and the Executive Director of the United Nations Children's Fund. Presented at International Conference on Primary Health Care, Alma-Ata, Union of the Soviet Socialist Republics, 6-12 September 1978. Order no. 1130001. Geneva, Switzerland. 79 pp.

World Health Organization. (1980). The Primary Health Worker, Rev. Ed. Geneva, Switzerland.

World Health Organization. Product Information Sheets, World Health Organization 1997. Ordering no. WHO/EPI/LHIS/97.01. Geneva, Switzerland.

World Health Organization. Report of 1991 Technet Consultation, Casablanca, Morocco. Order no. WHO/EPI/LHIS/92.1. Geneva, Switzerland.

World Health Organization. (1997). Technet Consultation, Manila, 12-16 February 1996. Order no. WHO/EPI/LHIS/97.02. Geneva Switzerland. Available on the web at http:// www.who.int/ gpo-coldchain/ technet.html.

World Health Organization 1991. (1996). "Solar Energy and Rural Health Care." WHO Fact Sheet N132. Geneva, Switzerland. Available on the web at http://www.who.int/inf/inf-fs/en/ fact132.html.

World Health Organization. (1993). Working Papers on Solar Energy and Health for the World Solar Summit, Paris, 1993. Logistics for Health 
Information Series. Order no. WHO/EPI/LHIS/

93.3. Geneva, Switzerland.

Zaffran, M. (coordinator) (1993). Report on Solar

Energy and Health: for the World Solar Summit,

Paris 1993. World Health Organization

Expanded Programme on Immunization.

Order no. WHO/EPI/LHIS/93.2. Geneva,

Switzerland.

Zaffran, M. "Solar Refrigeration for the Storage

of Vaccines in the Expanded Programme on Immunization in Developing Countries"

\section{GLOSSARY}

Alternating Current (AC)—Electric current in which the direction of flow oscillates at frequent, regular intervals.

Altitude-The angle between the horizon (a horizontal plane) and the sun, measured in degrees.

Amorphous Silicon-A thin film PV silicon cell having no crystalline structure.

Ampere (amp) —Unit of electric current measuring the flow of electrons per unit time.

Ampere-Hour (Ah) - The quantity of electrical energy equal to the flow of current of one ampere for one hour.

Angle of Incidence-Angle that references the sun's radiation striking a surface. A "normal" angle of incidence refers to the sun striking a surface at a $90^{\circ}$ (or perpendicular) angle.

Annualized Cost-The equivalent annual cost of a project if the expenses are treated as being equal each year. The discounted total of the annualized costs over the project lifetime is equal to the net present cost (NPC) of the project.

Array-A mechanically integrated configuration of modules together with support structure, designed to form a DC power-producing unit.

Azimuth-Angle between true south and the point directly below the location of the sun. Measured in degrees.

Battery-Two or more "cells" electrically connected for storing electrical energy.

Battery Capacity-Generally, the total number of ampere-hours that can be withdrawn from a fully charged cell or battery. The energy storage capacity is the ampere hour capacity multiplied by the battery voltage.

Battery Cell-A galvanic cell for storage of electrical energy. This cell after being discharged may be restored to a fully charged condition by an electric current.

Battery Cycle Life-The number of cycles, to a specified depth of discharge, that a cell or battery can undergo before failing to meet its specified capacity or efficiency performance criteria.

Battery Self Discharge-Self-discharge is the loss of otherwise usable chemical energy by spontaneous currents within the cell or battery regardless of its connections to an external circuit. 
Battery State of Charge-Percentage of full charge or $100 \%$ minus the depth of discharge (see depth of discharge).

Charge Controller-A device that controls the charging rate and/or state of charge for batteries.

Charge Rate-The current applied to a cell or battery to restore its available capacity.

Cold Chain-System of people and equipment that attempts to keep vaccines at proper temperatures as they are distributed from the manufacturer to the locations where they are administered.

Concentrator-An optical component of a photovoltaic array used to direct and increase the amount of incident sunlight on a solar cell.

Conversion Efficiency (Cell) - The ratio of the electricity energy produced by a photovoltaic cell (under full sun conditions) to the energy from incident sunlight on the cell.

Cost of Energy-The cost per unit of energy that, if held constant through the analysis period, would provide the same net present revenue value as the net present cost of the system.

Crystalline Silicon-A type of PV cell made from a single crystal or polycrystalline slice of silicon.

Current-The flow of electric charge in a conductor between two points having a difference in potential (voltage).

Cut-In Speed-The minimum wind speed at which a particular wind turbine will produce energy.

Cut-Out Speed-The speed at which a particular wind turbine will reduce its power output in order to protect itself from excessive wind speeds. Most small wind turbines do this by tilting out of the wind.

Days of Autonomy-The number of consecutive days a stand-alone system will meet a defined load without energy input.

Deep Cycle Battery-Type of battery that can be discharged to a large fraction of capacity many times without damaging the battery.

Depth of Discharge (DOD) - The amount of ampere-hours removed from a fully charged cell or battery, expressed as a percentage of rated capacity.

Design Month-The month having the lowest RE energy production to load ratio.

Direct Current (DC)—Electric current flowing in one direction.
Discharge Rate-The current removed over a specific period of time from a cell or battery.

Disconnect-Switch gear used to connect or disconnect components in a stand-alone system

Duty Cycle-The ratio of active time to total time. Used to describe the operating regime of appliances or loads in stand-alone systems.

Efficiency-The ratio of output power to input power. Expressed in percent.

Electric Circuit-A complete path followed by electrons from a power source to a load and back to source.

Electric Current-Magnitude of the flow of electrons.

Electrolyte-A conducting medium in which the flow of electric takes place by migration of ions. The electrolyte for a lead-acid storage cell is an aqueous solution of sulfuric acid.

Equalization-The process of mixing the electrolyte in batteries by periodically overcharging the batteries for a short period.

Grid-The network of transmission lines, distribution lines, and transformers used in central power systems.

Health - A state of physical, mental and social wellbeing, not merely the absence of infirmity.

Insolation-The solar radiation incident on an area. Usually expressed in watts per square meter $\left(\mathrm{W} / \mathrm{m}^{2}\right)$.

Inverter-A solid state device that changes a DC input to an AC output.

IV Curve-The graphical representation of the current versus the voltage of a photovoltaic cell, module, or array as the load is increased from zero voltage to maximum voltage. Typically measured at 1000 watts per square meter $\left(\mathrm{kW} / \mathrm{m}^{2}\right)$ of solar insulation at a specific cell temperature.

Kilowatt (kW)—One thousand watts.

Kilowatt Hour (kWh)—One thousand watt hours.

Life-Cycle Cost-An estimate of the cost of owning and operating a system for the period of its useful life; usually expressed in terms of the present value of all costs incurred over the lifetime of the system.

Load-The amount of electrical power being consumed at any given moment. Also, any device or appliance that is using power. 
Maximum Power Point-The operating point on a PV array IV curve where maximum power is delivered.

Module (Panel)_A predetermined electrical configuration of solar cells laminated into a protected assembly.

NEC - An abbreviation for the National Electric Code which contains safety guidelines for all types of electrical installations. Article 690 pertains to solar photovoltaic systems.

Net Present Cost (NPC) - The value in the base year (usually the present year) of all expenses associated with a project.

Nominal Voltage-A reference voltage used to describe batteries, modules, or systems (i.e., a 12-volt or 24-volt battery, module or system).

$\mathrm{Ohm}$ - A unit of electrical resistance measurement.

Open Circuit Voltage-The maximum possible voltage across a photovoltaic array.

Orientation-Placement according to the directions, N, S, E, W; azimuth is the measure in degrees from true south.

Panel-See module.

Parallel Connection-The method of interconnecting electricity-producing devices or power consuming devices, so that the voltage is constant but the current is additive.

Peak Load-The maximum load or electrical power consumption occurring in a period of time.

Peak Sun Hours-The equivalent number of hours per day when solar irradiance averages $1000 \mathrm{w} / \mathrm{m}^{2}$.

Peak Watt (Wp)-The amount of power a photovoltaic device will produce during peak insolation periods when the cell is faced directly at the sun.

Photovoltaic (PV) Cell-A cell that generates electrical energy when incident solar radiation falls on it.

Photovoltaic (PV) System-An installed aggregate of solar array, power conditioning and other subsystems providing power to a given application.

Power Conditioning-The electrical equipment used to convert power from a photovoltaic array into a form suitable to meet the power supply requirements of more traditional loads. Loosely, a collective term for inverter, transformer, voltage regulator, meters, switches, and controls.
Power Curve-A graphical representation of a wind turbine's power output as a function of wind speed.

Primary Health care-Essential health care based upon practical, scientifically sound, and socially acceptable methods and technology which addresses the main health problems in the community and provides preventive, curative and rehabilitative services.

Remote Site-Site which is not located near a utility grid.

Renewable Energy (RE) - Energy produced by non fossil fuel or nuclear means. Includes energy produced from PV, wind turbines, hydro-electric and biomass.

Series Connection-A method of interconnecting electricity producing devices or power using devices so that the current remains constant and the voltage is additive.

Short Circuit Current-Current measured when a PV cell (module) is not connected to a load or other resistance.

Single-Crystal Silicon-A material formed from a single silicon crystal.

Solar Cell-Photovoltaic cell.

Solar Thermal Electric-Method of producing electricity from solar energy by concentrating sunlight on a working fluid which changes phase to drive a turbine generator.

Stand-Alone System-A system that operates independently of the utility lines. It may draw supplementary power from the utility but is not capable of providing power to the utility.

Standards of Acceptance-A set of characteristics, attributes, features and performance criteria which establishes the minimum acceptable quality and value of products and services. In the context of health care, these standards are adopted by the purchaser or authority responsible for procuring health care systems.

State-of-Charge-The available capacity in a cell or battery expressed as a percentage of rated capacity. For example, if 25-ampere-hours have been removed from a fully charged 100 -ampere-hours cell, the new state of charge is $75 \%$.

Surge Capacity-The ability of an inverter or generator to deliver high currents for short periods of time such as when starting motors. 
Temperature Compensation-An allowance made in charge controller set points for changing battery temperatures.

Tilt Angle-Angle of inclination of collector as measured in degrees from the horizontal.

Volt, Voltage (V)-A unit of measurement of the force given to electrons in an electric circuit; electric potential.

Watt, Wattage (W)-Measure of electric power. Watts $=$ volts $\mathrm{x}$ amps.

Watt-Hour (Wh) —A quantity of electrical energy when one watt is used for one hour.

WHO-World Health Organization

Wind Turbine-A device that converts the energy of moving air into electricity.

\section{ABOUT THE AUTHORS}

\section{Ken Olson}

Ken Olson is Co-Founder and Executive Director of Solar Energy International (SEI), a non-profit educational organization. SEI provides education, training, and technical assistance in the use of renewable energy and environmental building technologies.

Ken is a vocational educator and renewable energy consultant who has worked extensively in Latin America. Since 1989, Ken has provided technical assistance, training, evaluation, and planning services in order to provide rural health clinics in developing countries with reliable electrical power from renewable energy. He has written and contributed to numerous technical publications about the design and installation of renewable energy systems that provide power from sun, wind, and water resources.

\section{Contact Information:}

Ken Olson

Solar Energy International

PO Box 715

Carbondale, CO 81623

Telephone: 970-963-8855

Fax: 970-963-8866

E-mail: sei@solarenergy.org

Web site: www.solarenergy.org

\section{Antonio "'Tony" " C. Jimenez}

A graduate of the University of Colorado (B.S. Engineering Physics 1990) and Colorado State University (M.S. Mechanical Engineering 1998), Tony Jimenez has worked in NREL's Village Power Team since 1995 performing system-sizing analysis on many proposed hybrid installations. He has also worked on renewable and hybrid system applications, such as this guide, and on the development of hybrid system sizing and analysis tools. 


\section{Notice:}

This report was prepared as an account of work sponsored by an agency of the United States government. Neither the United States government nor any agency thereof, nor any of their employees, makes any warranty, express or implied, or assumes any legal liability or responsibility for the accuracy, completeness, or usefulness of any information, apparatus, product, or process disclosed, or represents that its use would not infringe privately owned rights. Reference herein to any specific commercial product, process, or service by trade name, trademark, manufacturer, or otherwise does not necessarily constitute or imply its endorsement, recommendation, or favoring by the United States government or any agency thereof. The views and opinions of authors expressed herein do not necessarily state or reflect those of the United States government or any agency thereof.

Available to DOE and DOE contractors from:

Office of Scientific and Technical Information (OSTI)

P.O. Box 62

Oak Ridge, TN 37831

Prices available by calling (423) 576-8401

Available to the public from:

National Technical Information Service (NTIS)

U.S. Department of Commerce

5285 Port Royal Road

Springfield, VA 22161

(703) 487-4650 


\section{b) \\ Renewables for Sustainable Village Power}

This is the first in a series of rural applications guidebooks that the National Renewable Energy Laboratory (NREL) Village Power Program is commissioning to couple commercial renewable systems with rural applications. The guidebooks are complemented by NREL Village Power Program development activities, international pilot projects, and visiting professionals program. For more information on the NREL Village Power Program, please visit the Renewables for Sustainable Village Power web site:

\section{http://www.rsvp.nrel.gov/rsvp/}

Produced for the

U.S. Department of Energy

1000 Independence Avenue, SW

Washington, DC 20585

by the National Renewable Energy Laboratory, a DOE national laboratory.

NREL/BK-500-25233

September 1998 